\title{
Response Priming with Horizontally and Vertically Moving Primes: A Comparison of German, Malaysian, and Japanese Subjects
}

\author{
Christina Bermeitinger ${ }^{1}$, Laura Kalbfleisch ${ }^{1}$, Katharina Schäfer ${ }^{1}$, Alfred Lim², Hannah \\ Goymann', Lea Reuter', and Steve M. J. Janssen²
}

\author{
1 University of Hildesheim, Germany \\ ${ }^{2}$ University of Nottingham Malaysia, Malaysia
}

ABSTRACT

\author{
KEYWORDS \\ response priming \\ motion \\ movement \\ negative compatibility effect \\ inhibition \\ cultural differences \\ Germany \\ Japan \\ Malaysia \\ horizontal and vertical motion
}

\begin{abstract}
Response priming refers to the finding that a prime preceding a target influences the response to the target. With German subjects, horizontally moving dots as primes, and static arrows as targets, there are typically faster responses to compatible (i.e., prime and target are associated with the same response) as compared to incompatible targets (i.e., positive compatibility effect, PCE) with short stimulus onset asynchronies (SOAs). In contrast, with longer SOAs, subjects respond faster to incompatible as compared to compatible targets (i.e., negative compatibility effect, NCE). In the present study, we extended the evidence by adding vertically oriented materials. Furthermore, we tested subjects from Malaysia and Japan, where the vertical orientation is more present in daily life, and compared them to German subjects to investigate whether the amount of experience with one orientation influences the compatibility effects on this orientation. Overall, we found pronounced PCEs in the short SOA (i.e., $150 \mathrm{~ms}$ ) but only reduced PCEs in the longer SOAs (i.e., 350,550 , and $750 \mathrm{~ms}$ ) across all countries and orientations. There were no differences between the German and Malaysian samples, but the Japanese sample showed larger PCEs in the longer SOAs compared to both other samples. Furthermore, we found larger PCEs for horizontal than vertical materials in the short SOA and larger PCEs for vertical than horizontal materials in the longer SOAs. We discuss our findings in light of theories and findings on compatibility effects as well as attentional mechanisms.
\end{abstract}

\section{INTRODUCTION}

Motions are inherently involved in spatial orientation and spatial representation (e.g., Berthoz \& Viaud-Delmon, 1999). On the one hand, people use their own motion to structure the environment spatially, for example, by adjusting their body midline as a reference point to distinguish between left and right. On the other hand, perceived motion is particularly able to quickly draw attention and to activate orientation or other responses. Specifically, motion seems to have the capacity to trigger responses rapidly and involuntarily (e.g., Machado et al., 2007). The present study was concerned with the question whether vertical and horizontal motions trigger responses differently and whether daily use of different orientations, especially in reading and writing, has an influence on the processing of vertical and horizontal motions and their impact to facilitate or inhibit responses. We first describe one cognitive paradigmthe response priming paradigm-that is well suited to investigate the influence of perceived spatially oriented motion and how these motions trigger actions. We then describe several theoretical explanations that have been developed for explaining the typical pattern resulting from response priming with masked static primes. Some of them can be applied to the results using clearly visible horizontal motions as primes. We then discuss question of processing differences for differently oriented material and possible influences of reading/writing orientations.

Corresponding author: Christina Bermeitinger, University of Hildesheim, Department of Psychology, Universitätsplatz 1, D - 31141 Hildesheim, Germany. E-mail: bermeitinger@uni-hildesheim.de 


\section{Response Priming Paradigm}

Response priming (for a review see, e.g., Schmidt et al., 2011) as a behavioural measure assesses the effects of motor pre-activations (and/ or perceptual/semantic preactivation) from a prime event (i.e., the first stimulus, to which a subject does not have to respond) on the processing of a target event (i.e., the second stimulus, to which a subject has to respond).

Response priming has mainly been investigated using shape and colour stimuli. For example, in the study by Eimer and Schlaghecken (2002), primes and targets were squares and diamonds, and the subjects' task was to quickly and accurately respond to the shape of the target (e.g., left button for squares and right button for diamonds). In these studies, reaction times (RTs) to the target are typically reduced when the preceding prime stimulus and the target are associated with the same response (i.e., primes and targets are congruent, consistent, or compatible, e.g., both are squares) compared to targets associated with a different response (i.e., primes and targets are incongruent, inconsistent, or incompatible, e.g., the prime is a square and the target is a diamond). Given specific conditions (e.g., prime not clearly visible and sufficient time between prime onset and target onset), there are faster responses to incompatible compared to compatible targets.

Bermeitinger (2013) introduced a variant of response priming in which horizontally moving rows of dots were used as primes for static arrow targets to investigate pre-activations of directional (i.e., left and right) motions (there were two previous response priming studies in which circular or rotational motions were used: Mattler \& Fendrich, 2007; Sarkheil et al., 2008). The time-course of compatibility effects was investigated by use of stimulus onset asynchronies (SOAs) ranging from 50 to $350 \mathrm{~ms}-\mathrm{SOA}$ was varied in steps of approximately $50 \mathrm{~ms}$ (this is similar to the SOA manipulation in steps of $42 \mathrm{~ms}$ from 0 to 296 ms of Lingnau \& Vorberg, 2005, who investigated the time course of central and peripheral masked primes)-and an even longer SOA of $500 \mathrm{~ms}$. Bermeitinger found compatibility effects (i.e., responses to incompatible targets minus responses to compatible targets) with such moving prime stimuli. The sign of the compatibility effect depended on the SOA between prime and target. In general, with an SOA of $50 \mathrm{~ms}$, no compatibility effect was observed. With SOAs of 100 and $150 \mathrm{~ms}$, faster reactions to compatible targets emerged (positive compatibility effects, PCEs). However, with SOAs between 250 and $500 \mathrm{~ms}$, faster reactions were made to incompatible targets (negative compatibility effects, NCEs). Even with a very long SOA of 1,000 ms, an NCE was obvious (Bermeitinger \& Wentura, 2016).

This pattern appeared whether the SOA was varied between or within subjects, independently of prime duration (Bermeitinger, 2013; Hackländer et al., 2015), and with forced-choice as well as free-choice tasks (Bermeitinger \& Hackländer, 2018). Also, in experiments using a single moving dot as a prime (instead of a row of dots), the same pattern was found: PCEs following shorter SOAs and NCEs following longer SOAs, but with a delay in its time course; positive effects up to an SOA of $360 \mathrm{~ms}$ and negative effects with SOAs of 800 to 1,200 ms (Bermeitinger \& Wentura, 2016). Taken together, with horizontally moving row-of-dots primes, SOAs of approximately $150 \mathrm{~ms}$ reliably produce PCEs, and SOAs of approximately $360 \mathrm{~ms}$ reliably produce NCEs. Negative compatibility effects could be found even with very long SOAs of 1,000 and 1,200 ms. Findings to date do not provide any evidence for further reversals from NCEs to PCEs or vice versa.

Note that in classical studies on response priming, the same stimuli were used for primes and targets. In these studies, perceptual priming and response priming cannot be distinguished. However, in the current study, we used moving rows of dots as primes and static arrow targets. This was in order to reduce perceptual overlap between primes and targets. Thus, explanations in terms of perceptual overlap between prime and target are not applicable and this differentiation is not of central importance to our work.

\section{Explanations of Compatibility Effects}

Positive compatibility effects can be explained by motor pre-activations caused by the prime, which lead to response advantages when a compatible target appears (see especially the theory of direct parameter specification, Neumann, 1990, and extensions of it, e.g., the actiontrigger theory, Kiesel et al., 2007; Kunde et al., 2003, or the rapid-chase theory, Schmidt et al., 2006). However, these motor pre-activations have difficulties explaining NCEs at longer SOAs. Several theories have been developed to explain the faster reactions to incompatible trials (for a review see, e.g., Kiesel et al., 2007), especially for masked primes. Some authors (e.g., Jaśkowski et al., 2008; Lleras \& Enns, 2004) have argued that NCEs only occur if primes and masks/targets share common features. The NCEs result either from object updating (e.g., Lleras \& Enns, 2004) or they reflect mask-induced activations that inhibit ongoing action. However, these interpretations have not held up due to the fact that NCEs were also found without such common features of mask and prime (e.g., Klapp, 2005; Schlaghecken \& Eimer, 2006; Schlaghecken et al. 2009), and even without any mask or intervening object, for example in the case of moving primes (e.g., Bermeitinger, 2013).

Schlaghecken, Eimer, and colleagues (e.g., Schlaghecken \& Eimer, 2002) argued that NCEs reflect an inhibition mechanism in low-level motor control as an automatic consequence after initial response activation. As long as there is sensory evidence for an activated response, PCEs will result. Without further sensory evidence, for example, due to the introduction of the mask, early motor activation tendencies are no longer supported. Positive priming is counteracted by inhibition to prevent premature responding; this results in an NCE. Regarding NCEs with clearly visible motion primes, one might argue, in accordance with the inhibition account of Schlaghecken and Eimer (2006), that rapidly and involuntarily triggered response activations-in our case, caused by perceived motion-might be inhibited very quickly if they are classified as unfounded (although there is further sensory evidence)-resulting in NCEs. This classification needs some time. Thus, for short SOAs, PCEs emerge.

Klauer and Dittrich (2010) described a further supplementary mechanism contributing to PCEs versus NCEs, which is thought as acting at a more central categorization level. Some key assumptions of 
their evaluation window account are: (a) subjects evaluate all task relevant as well as task irrelevant incoming events across a time window with respect to the task, (b) there are separate counters accumulating incoming evidence for their respective categories, (c) subjects learn to partition the stream of incoming evidence into distinct episodes; they use one stimulus as a go signal to open the "evaluation window", (d) optimally, only evidence provided by the target is counted for the evaluation and the corresponding response, that is, the onset of the evaluation window starts to close before the target. However, to enable fast decisions in speeded reaction time tasks, the evaluation window has to be opened as fast as possible (i.e., anticipatorily). Thus, activation from the preceding context (i.e., prime) is counted as evidence for target decisions as well; (e) for decisions about stimuli belonging to one response category, changes count more and can be detected easier when starting from a lower compared to a higher level (i.e., WeberFechner law), and, in turn, (f) NCEs will result if the prime is outside the evaluation window: A prime increases the corresponding counter previously, resulting in more effort to detect further increases by a target of the same response category (i.e., compatible trials) whereas the counter of the other response category (i.e., incompatible trials) starts at a low level when the evaluation window is opened. In contrast, PCEs will result if the primes fall inside the evaluation window.

With motion primes, it seems that the onset of the target is especially unpredictable in longer SOA conditions. In short SOAs, motion primes seem to trigger the opening of the evaluation window-resulting in PCEs. In longer SOAs, however, possibly due to the longer temporal gap between prime onset and target onset, motion primes do not act as a "go signal" for opening the evaluation window-resulting in NCEs. In contrast, with static primes, the partitioning of the stream and the prediction of the target's onset seems to be easier, and the prime can act as a go signal in shorter and longer SOAs, resulting in PCEs even at longer delays.

Bermeitinger et al. (2019) demonstrated that a self-inhibition mechanism in low-level motor control (e.g., Schlaghecken \& Eimer, 2006) in combination with the evaluation window account (Klauer \& Dittrich, 2010) is able to explain (or predict) the results with motion primes.

However, there are other mechanisms that might contribute to this pattern of results, such as attentional mechanisms. These mechanisms seem promising as the time course in some attentional paradigms mirrors the time course found for response priming using motion primes (see also Bermeitinger, 2013; but see Bermeitinger et al., 2019). Specifically, using Posner's (1980) spatial cueing paradigm, it has been found that performance in making a saccadic or manual response to a target is typically slower on trials in which the target is presented at a previously cued location as compared to an uncued location, at least when the time interval between cue and target onset (cue target onset asynchrony; CTOA) is longer than about $200 \mathrm{~ms}$ (e.g., Hilchey et al., 2014). Such a delay in responses to targets appearing at previously cued locations, relative to uncued locations, is termed inhibition of return (IOR; Posner et al., 1985). However, at shorter CTOAs, positive cueing effects are observed. The time course of positive cueing effects and IOR shares a similar pattern to that of PCEs and NCEs with motion primes in response priming: Positive cueing effects can be found at CTOAs shorter than around $200 \mathrm{~ms}$ and IOR is found at CTOAs longer than around 200 ms (e.g., Klein, 2000), which are suggested to be caused by the "winner-take-all" competition between inhibitory mechanisms and the transient activity of exogenous orienting (Lim et al., 2018). Until now, it is unclear whether NCEs play a role in IOR and further studies are needed to better understand and distinguish the mechanisms responsible for IOR and NCEs.

\section{Horizontally Versus Vertically Oriented Stimuli}

Generally, we can distinguish between two spatial orientations that are of special interest when investigating the influences of spatial processing and, in turn, perceived motions-the horizontal and vertical orientations. Up to now, response priming with moving stimuli has not been done with vertically moving stimuli and there are only very few examples for response priming experiments with static material in which the vertical axis has been addressed (Klauer \& Dittrich, 2010). That is, it is unclear which pattern might result with vertically oriented stimuli and which theoretical explanations are appropriate for it. However, with other paradigms and/or static materials, there are several findings for differences or commonalities using vertically versus horizontally arranged stimuli.

For example, with static materials, one typical result is that spatial compatibility effects are larger with horizontal than vertical materials, an effect also called left/right prevalence when investigated with spatial compatibility tasks in which location is the to-be-classified feature of the target (Nicoletti \& Umiltà, 1984, 1985; Nicoletti et al., 1988). Similar patterns of results are also observed with Simon tasks, a variant of the spatial compatibility task in which the location is not task relevant (Nicoletti \& Umiltà, 1985; Nicoletti et al., 1988; Rubichi et al., 2005; Rubichi et al., 2006; Vallesi et al., 2005; Wiegand \& Wascher, 2005), as well as in response priming with static material. There, smaller compatibility effects with vertical compared to horizontal stimuli can be detected by inspection. However, they can also be explained by other differences (Klauer \& Dittrich, 2010).

Some authors assume that different neural mechanisms contribute to horizontal versus vertical spatial compatibility effects (e.g., Vallesi et al., 2005; Wiegand \& Wascher, 2005). Another approach assumes that the relative salience of one of the two dimensions (vertical vs. horizontal) leads to the prevalence effects found in previous studies (e.g., Rubichi et al., 2005; Rubichi et al., 2006). Furthermore, the role of training has been discussed. Rubichi et al. (2005) suggested that the distinction between left and right side is more needed in daily life and, therefore, highly trained, whereas the distinction between up and down is less important. Based on findings on the influence of learned reactions to Simon effects (e.g., Taguchi, 2010), Rubichi et al. (2005) argued that the left/right prevalence is mainly driven by training. When looking at the IOR effect, there are also some findings for the influence of environmental regularities (e.g., Spalek \& Hammad, 2005). 
TABLE 1.

Short Overview of Current Reading/Writing Directions of Scripts in Some Languages/Countries

\begin{tabular}{|c|c|}
\hline Language (country, region) & Reading/writing direction \\
\hline Arabic & horizontal from right to left \\
\hline $\begin{array}{l}\text { Chinese (at least Mandarin, } \\
\text { Cantonese, Hokkien) }\end{array}$ & $\begin{array}{l}\text { most often horizontal from left } \\
\text { to right; sometimes vertically } \\
\text { oriented (top to bottom) }\end{array}$ \\
\hline East Asian & see Taiwanese/Japanese \\
\hline Farsi & horizontal from right to left \\
\hline French & horizontal from left to right \\
\hline Hebrew & horizontal from right to left \\
\hline Hindi & horizontal from left to right \\
\hline Italian & horizontal from left to right \\
\hline Japanese & $\begin{array}{l}\text { traditionally vertical from top to } \\
\text { bottom; alternatively horizontal } \\
\text { from left to right }\end{array}$ \\
\hline \multicolumn{2}{|l|}{ Malaysia } \\
\hline ...Chinese Malaysian & see Chinese \\
\hline ....Malay & horizontal from left to right \\
\hline ...Indian (Tamil) & horizontal from left to right \\
\hline Middle/Near East & horizontal from right to left \\
\hline Taiwanese & $\begin{array}{l}\text { traditionally vertical from top to } \\
\text { bottom }\end{array}$ \\
\hline Tunisia & horizontal from right to left \\
\hline Urdu & horizontal from left to right \\
\hline Vietnamese & can be vertically oriented \\
\hline $\begin{array}{l}\text { Western (English, German, } \\
\text { Spanish, etc.) }\end{array}$ & horizontal from left to right \\
\hline
\end{tabular}

Note. Source: https://www.w3.org/International/questions/qa-scripts.en\#what (last access 12.12.2018).

\section{Reading and Writing Orientation}

An essential spatial aspect in daily life that is closely related to learning and training is reading and writing direction (for current reading/ writing directions in some languages/countries, see Table 1). There are several studies that have examined the relationship between reading/writing orientation and spatial processing or biases. For example, Chan and Bergen (2005) showed, with samples of English, Chinese, and Taiwanese subjects, that attention is drawn first to locations at which the text starts in the corresponding writing system. Spalek and Hammad (2005) reported a larger IOR bias when the cue was presented on the left in English-speaking Canadians and an opposite rightto-left bias was observed in Arabic-speaking Egyptians. Fagard and Dahmen (2003) compared the performance of French and Tunisian children in three visuo-spatial tasks: a line bisection task, a circledrawing task, and a dot-filling task. The results showed that the French children bisected the line to the left of the true centre (but see Ishii et al., 2011, for Japanese vs. English speaking adults), used increasing counter-clockwise movements when drawing circles, and filled more dots when going from left to right compared to Tunisian children, suggesting visuo-spatial behaviour might be influenced by reading and writing habits. Furthermore, preferences for directions (e.g., in pictures) are strongly related to reading/writing habits, with subjects preferring stimuli oriented (or moving) in the direction corresponding to their own writing system (e.g., Maass \& Russo, 2003, with Italian vs. Arabic subjects; Chokron \& De Agostini, 2000, with French vs. Israeli [Hebrew] subjects; Ishii et al., 2011, with English vs. Japanese reading subjects; Liu et al., 2013, with Taiwanese subjects; but see, Treiman \& Allaith, 2013, who found no difference between Arabic reading and English reading children). Other studies focused on differences in eye movements related to the writing system. For example, visual scanning patterns with more vertical than horizontal saccades were found in East Asian subjects, compared to Western subjects and subjects from Middle/Near East (Abed, 1991).

In sum, reading and writing experience-and thus culturally embedded habits-are strongly related to differences in general spatial processing. It can be assumed that the processing of motion directionsand their impact on response activations-in our response priming task is also related to reading and writing experience. For this reason, we tested subjects from three countries to better understand the effects of environment regularities on compatibility effects: German subjects (all experiments), whose reading direction is mostly horizontally from left to right, as well as Chinese Malaysian (Experiment 3) and Japanese (Experiment 4) subjects who are also confronted with vertical reading and writing in daily life.

\section{The Present Study}

The current study had three main aims. The first was to examine whether response priming, previously only observed with horizontal movements, could also be observed with vertical ones. The second aim was to examine whether response priming with vertical materials showed the same time course as with horizontal ones. The third aim was to investigate whether daily training and use of different reading and writing orientations influences the pre-activations for vertical/ horizontal materials.

To investigate this influence of daily training, we examined whether the compatibility effect for vertically oriented materials would be larger for subjects who would more accustomed to reading and writing vertically (i.e., Chinese Malaysian and even more so Japanese students). When PCEs and NCEs in response priming with motion primes were influenced by training, we expected larger compatibility effects with vertical materials in Japanese and Chinese Malaysian than in German subjects, with Japanese subjects showing a larger difference compared to German subjects than Chinese Malaysian subjects because the vertical reading/writing orientation is more present in Japan and in Japanese language. As subjects from all tested countries have profound expertise and skills in horizontal reading/writing, we expected no differences for the PCEs and NCEs with horizontal materials.

Based on previous experiments, we calculated the sample sizes needed to find compatibility effects in each condition. The PCEs and NCEs with horizontal materials in Bermeitinger (2013) were substantial: The PCE at SOAs of about $150 \mathrm{~ms}$ varied from $\mathrm{d}=0.59$ to 1.06 ( $\mathrm{M}$ $=0.83$ ) across experiments. The NCE at SOAs of about $350 \mathrm{~ms}$ varied from $\mathrm{d}=0.61$ to $1.05(M=0.78)$. With respect to the mean effect sizes, it can be stated that the compatibility effects can be detected with the probability of $1-\beta=.80$ ( $\alpha=.05$, two-tailed $)$ if one uses a sample size 
of at least $N=14$ for PCEs in shorter SOAs and $N=15$ for NCEs in longer SOAs (Power calculations were computed with $\mathrm{G}^{\star}$ Power; Faul et al., 2007). Thus, we used sample sizes of $N>14$ in each condition of the experiments.

\section{EXPERIMENT 1}

With Experiment 1, we conducted the first experiment with vertical motions as primes. We used only vertical motions as primes and we varied the SOA within subjects. Furthermore, we made the experiment comparable in almost all other aspects to our previous experiments with horizontal motions (e.g., Bermeitinger, 2013). If there are comparable mechanisms and a comparable time course for the processing of horizontal and vertical motion, we expected to find a compatibility effect in the shorter SOA of $160 \mathrm{~ms}$ and a smaller, or even no, compatibility effect in the longer SOA of $360 \mathrm{~ms}$.

\section{Method}

\section{SUBJECTS}

In total, 70 students from the University of Hildesheim were tested. Two subjects were excluded due to technical problems during data recording. Of the remaining 68 subjects, 61 were female and 7 were male. Sixty-four subjects were right-handed, three were left-handed, and one had no handedness dominance. The median age was 20.5 years (range: 18-35 years). The subjects participated in exchange for partial course credits.

\section{DESIGN}

A 3 (Motion direction: upwards, downwards, neutral) $\times 2$ (Arrow direction: upwards, downwards) $\times 2$ (SOA: $160 \mathrm{~ms}, 360 \mathrm{~ms}$ ) design was used. All factors were varied within subjects, Motion direction (i.e., prime) and Arrow direction (i.e., target) trial-by-trial, SOA in a block-wise manner; and the order of SOA was counterbalanced across subjects. The present design allows prime onset to reliably predict when the target will occur.

In the tradition of priming experiments, we focused on the compatible (dots moved upwards and the arrow pointed upwards; dots moved downwards and the arrow pointed downwards) and incompatible (dots moved upwards and the arrow pointed downwards; dots moved downwards and the arrow pointed upwards) conditions. The compatibility effect was computed as the target response time difference between incompatible and compatible trials.

\section{MATERIALS}

All stimuli were presented in black on a white background. The materials used in Bermeitinger (2013) were rotated by $90^{\circ}$. The primes were rows of $10.5,11$, or 11.5 dots; each dot was approximately $0.38^{\circ}$ visual angle $(0.4 \mathrm{~cm})$ in diameter, the distance from one dot to the next dot was approximately $0.96^{\circ}$ visual angle $(1.0 \mathrm{~cm})$, and the whole row measured approximately $13.78^{\circ}$ visual angle $(14.5 \mathrm{~cm})$. Two arrows were used as target stimuli, one pointing upwards and one pointing downwards; the arrows were approximately $3.34^{\circ}$ visual angle $(3.5 \mathrm{~cm})$ in height and $0.96^{\circ}$ visual angle $(1.0 \mathrm{~cm})$ in width.

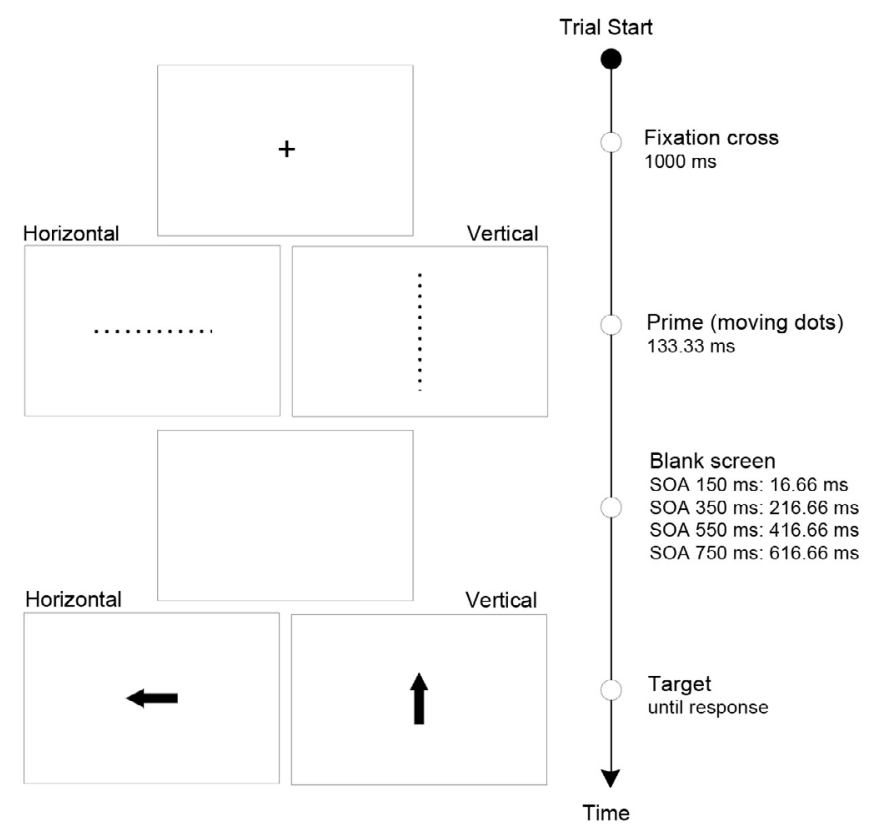

\section{FIGURE 1.}

Experimental design used, proceeding temporally from top to bottom. The dots moved rightwards or leftwards in the horizontal condition, and upwards or downwards in the vertical condition (in the neutral conditions, half of the dots moved rightwards/upwards, and have of the dots moved leftwards/downwards - see text). After a variable delay, a rightwards vs. leftwards (in the horizontal condition) or upwards vs. downwards (in the vertical condition) arrow to which the subjects had to make a keyboard response (times were given for Experiments 2 to 4 ). 
The prime event started with the presentation of the row at the centre of the screen (see Figure 1). To instantiate the movement, the dots were shifted from their original position in steps of $0.16^{\circ}$ visual angle $(0.17 \mathrm{~cm})$ upwards or downwards. After six steps, a dot had reached the original position of its neighbouring dot and the movement started again from the screen's centre (original row position). For each prime event, 11 frames were presented (i.e., there were 10 movement steps of the dots). For the compatible and incompatible conditions, the dots (i.e., the whole row) were moved upwards, or downwards. For the neutral conditions, the dots were either moved outwards (i.e., the 5.5 top dots of the row moved upwards, the 5.5 bottom dots of the row moved downwards, meaning that the central dot was split into two semicircles that drifted apart) or inwards (i.e., the 5.5 top dots of the row moved downwards, the 5.5 bottom dots of the row moved upwards, meaning that the central dot was split into two semicircles that progressively superimpose; for more details see Bermeitinger, 2013).

\section{PROCEDURE}

Subjects were individually tested in sound-attenuated chambers. The experiment was conducted using E-Prime software (Version 2) with standard desktop computers and 17 in. CRT monitors with a refresh rate of $75 \mathrm{~Hz}$. Stimulus presentation was synchronised with the vertical retrace signal of the monitor. Viewing distance was about $60 \mathrm{~cm}$. Demographic data were collected at the beginning of the experiment. German instructions appeared on the screen. Subjects were instructed to quickly and accurately categorise each arrow with regard to its direction. For up and down arrows, the response keys were the + and the Enter keys on the numeric pad on which up and down arrows were pasted, and subjects were instructed to press these keys with their right index finger / right thumb, respectively. The subjects were informed that the dots were irrelevant to the task.

The sequence of each trial was as follows (see Figure 1): first, a fixation stimulus (+) appeared at the centre of the screen for 1,000 ms. It was followed by the first row of dots, which was presented for one refresh cycle (i.e., $13.33 \mathrm{~ms}$ ). Then, the next 10 rows of dots were presented for the next 10 refresh cycles (resulting in a prime duration of overall $146.66 \mathrm{~ms}$. Note that after six refresh cycles, the row sequence started again from the original row). The prime event was followed by a blank screen of $13.33 \mathrm{~ms}$ in the short SOA condition (160 ms), and of $213.33 \mathrm{~ms}$ in the long SOA condition (360 ms). The blank screen was then followed by the target. The target remained on the screen until a response was made. The inter-trial interval was $400 \mathrm{~ms}$.
Each subject worked through four blocks with 36 trials each for the short as well as the long SOA condition (288 trials in total). Each block consisted of 12 compatible trials (six with dots moving upwards/ downwards, respectively), 12 incompatible trials (six with dots moving upwards/downwards, respectively), and 12 neutral trials (six with dots moving outwards and inwards, respectively); half of the trials had up arrow targets, the other half had down arrow targets. There was a short pause after each block. There was a practice phase with 12 trials before each SOA condition. The entire experiment (including instructions, practice trials, and breaks) took about 25 minutes to complete.

Before the practice phase of the first SOA and before the practice phase of the second SOA, there were short manipulations for another research question: subjects heard short pieces of music. At the beginning and end of the experiment, they were additionally queried regarding their mood. These manipulations and data were of no interest for the current study and were not presented here.

\section{Results}

Mean RTs were derived from correct responses. Outlying RTs that were 1.5 interquartile ranges above the third quartile with respect to the individual distribution of responses (Tukey, 1977), above 1,500 ms, or below $200 \mathrm{~ms}$ were discarded. Due to these error and outlier criteria, $4.59 \%$ of all trials had to be excluded (1.61\% of all due to errors) from the RT analyses. For all following analyses, if necessary (i.e., if the Mauchly's test of sphericity was significant), Greenhouse-Geisser corrected $F, p$, and $\eta_{p}{ }^{2}$ values are reported. Mean RTs and error rates are given in Table 2, and mean RT compatibility effects for each condition are shown in Figure 2. Effect sizes d for the compatibility effects of all experiments are given in Table 3. Analyses were conducted using IBM SPSS Statistics Version 26 (IBM Corp., 2018).

\section{REACTION TIMES}

Mean reaction times were examined with a repeated-measures ANOVA with the within-subjects factors of Compatibility (compatible, incompatible, neutral) and SOA (160 ms, $360 \mathrm{~ms})$; adding the Order of SOAs as a factor, there were no significant effects including this factor (all $p s>.11$ ). The main effect of compatibility was significant, $F(2,134)$ $=10.11, p<.001, \eta_{p}{ }^{2}=.131$; repeated contrasts showed significant differences between incompatible and neutral $(p<.001)$ but not between neutral and compatible trials $(p=.219)$. The main effect of SOA was significant too, $F(1,67)=53.05, p<.001, \eta_{\mathrm{p}}{ }^{2}=.442$, indicating faster responses in the $360 \mathrm{~ms}$ SOA condition compared to the $160 \mathrm{~ms}$ SOA condition. Most interestingly, the main effects were qualified by a sig-

\section{TABLE 2.}

Mean Response Times (SD in Parentheses) and Mean Error Rates (SD in Parentheses) of the Compatible, Incompatible, and Neutral Conditions for Each Stimulus Onset Asynchrony (160 ms, 360 ms) Condition of Experiment 1

\begin{tabular}{ccccccc}
\hline & \multicolumn{3}{c}{ Response time (in ms) } & \multicolumn{3}{c}{ Error rates (in \%) } \\
\cline { 2 - 7 } & Compatible & Incompatible & Neutral & Compatible & Incompatible & Neutral \\
\hline $160 \mathrm{~ms} \mathrm{SOA}$ & $362(36.56)$ & $374(37.17)$ & $366(35.08)$ & $1.16(1.66)$ & $1.90(2.03)$ & $1.81(2.62)$ \\
$360 \mathrm{~ms}$ SOA & $353(34.65)$ & $354(38.82)$ & $353(34.61)$ & $1.75(2.54)$ & $1.87(2.62)$ & $1.19(1.88)$ \\
\hline
\end{tabular}

Note. Only with vertically oriented material; Stimulus onset asynchrony (SOA) was varied block-wise within subjects. 


\section{TABLE 3.}

Effect Size (d) for the RT Compatibility Effects of Each SOA Condition and the Horizontal and Vertical Orientation of all Samples from Experiments 1 to 4

\begin{tabular}{lccc}
\hline \multicolumn{1}{c}{ Sample } & SOA & $\begin{array}{c}\text { Horizontal } \\
\text { orientation }\end{array}$ & $\begin{array}{c}\text { Vertical } \\
\text { orientation }\end{array}$ \\
\hline Experiment 1 & $160 \mathrm{~ms}$ & $/$ & 0.667 \\
& $360 \mathrm{~ms}$ & $/$ & 0.028 \\
\hline Experiment 2 & $150 \mathrm{~ms}$ & 1.193 & 1.146 \\
& $350 \mathrm{~ms}$ & 0.259 & 0.354 \\
& $550 \mathrm{~ms}$ & -0.385 & 0.300 \\
\hline Experiment 3, German & $150 \mathrm{~ms}$ & 1.192 & 0.738 \\
& $350 \mathrm{~ms}$ & 0.171 & 0.282 \\
& $550 \mathrm{~ms}$ & -0.041 & -0.110 \\
& $750 \mathrm{~ms}$ & 0.373 & 0.516 \\
\hline Experiment 3, Malaysian & $150 \mathrm{~ms}$ & 1.105 & 1.283 \\
& $350 \mathrm{~ms}$ & 0.795 & 0.487 \\
& $550 \mathrm{~ms}$ & -0.143 & 0.550 \\
& $750 \mathrm{~ms}$ & 0.515 & 0.592 \\
\hline Experiment 4, German & $150 \mathrm{~ms}$ & 1.298 & 1.313 \\
& $350 \mathrm{~ms}$ & 0.391 & 0.475 \\
\hline Experiment 4, Japanese & $150 \mathrm{~ms}$ & 1.195 & 0.689 \\
& $350 \mathrm{~ms}$ & 0.652 & 0.769 \\
\hline
\end{tabular}

nificant interaction of compatibility and SOA, $F(2,134)=16.99, p<$ $.001, \eta_{\mathrm{p}}{ }^{2}=.202$.

Therefore, we analysed the compatibility effects for each SOA separately. In the $160 \mathrm{~ms} \mathrm{SOA}$ condition, there was a significant compatibility effect, $t(67)=5.50, p<.001$, but, in the $360 \mathrm{~ms}$ SOA condition, there was not, $p=.82$.

\section{ERROR RATES}

The same ANOVA with the factors of compatibility and SOA for error rates revealed no significant main effects, both $p s>.15$. The interaction effect also missed the criterion for significance, $p=.06$.

\section{Discussion}

Experiment 1 was the first experiment in which vertical motions were used as primes in a response priming study. The pattern of results mirrors previous findings with horizontally moving primes (e.g., Bermeitinger, 2013), showing an interaction between compatibility and SOA: In the short SOA condition, subjects responded faster to compatible than incompatible trials. In the longer SOA condition, this PCE vanished completely. However, we found no NCE in the longer SOA. Compared to some previous findings with horizontal prime motions, this result does not seem completely uncommon. For example, Bermeitinger and Hackländer (2018) also found no NCE in forcedchoice trials in the longer SOA condition. Additionally, with other materials (single dots), PCEs turned into NCEs in even longer SOA conditions (Bermeitinger \& Wentura, 2016). However, the within-subjects manipulation of SOA might also have impeded the emergence of an NCE. Thus, in Experiment 2, we adapted several aspects, including a comparison to horizontal materials and an even longer SOA of $550 \mathrm{~ms}$.

\section{EXPERIMENT 2}

In Experiment 1, we observed PCEs with vertically oriented materials but only with an SOA of $160 \mathrm{~ms}$ (i.e., there was no significant effect in the condition with an SOA of $360 \mathrm{~ms}$ ). Because we did not include conditions in which we presented the materials horizontally, we decided to conduct a follow-up study in which we could compare response priming of vertical and horizontal motions with three different SOA conditions (between-subjects). To make the response conditions for horizontal and vertical materials as similar as possible, in the vertical condition, subjects had to respond only with their right hand (they had to use their right thumb and index finger to arrows pointing down or up, respectively). In the horizontal condition, they had to use their right index finger and middle finger to arrows pointing leftwards or rightwards, respectively. In addition, because NCEs may emerge later in response to vertical motion primes, we added a third SOA condition (550 ms).

Furthermore, to prepare the experiment for the use in Malaysia (Experiment 3) and Japan (Experiment 4), we changed two additional aspects. First, we used a refresh rate of $60 \mathrm{~Hz}$ (instead of $75 \mathrm{~Hz}$ ) in anticipation of the use of flat screens in Malaysia and Japan, which slowed down the general motion velocity by prolonging the presentation time of each slide from $13.33 \mathrm{~ms}$ to $16.66 \mathrm{~ms}$. Second, even though the sample was German, we used verbal English instructions, given via headphones, as we aimed to reduce a potential priming of the horizontal direction caused by the reading of written instructions. We used English instructions for all of our samples in Experiment 2, 3, and 4 to hold this point comparable for all samples, keeping in mind that English is not the mother tongue in these countries. One might argue that English might induce a left/right bias in our subjects. However,

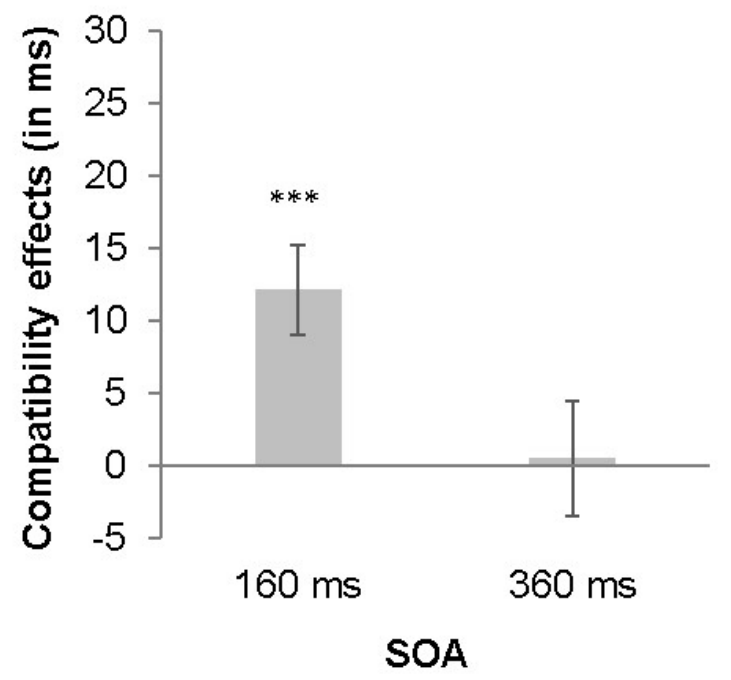

FIGURE 2.

Mean RT compatibility effects (mean RT incompatible-mean RT compatible) from the 160 and 360 ms stimulus onset asynchrony (SOA) conditions in Experiment 1 (with a German sample), only with vertically oriented materials; error bars represent the standard error of the mean $( \pm \mathrm{SE}) ; * * * 0.001$ 
at the Malaysian Campus, English is the language of instruction and the language present in everyday life. In Japan, the conversation (i.e., acquisition, welcoming etc.) between subjects and our experimenters was also in English. That is, these subjects would have been confronted with English in any case. In contrast, for German subjects, English and German are in the same reading/writing direction and the use of English did not induce another bias as the habitual preference. In order to keep the instructions together with the language constant (and to also keep constant the fact that English was not the mother tongue for any of our subjects), we decided to use English instructions for all subjects. To minimize the influence of spatial coding caused by the language, we used verbal instructions.

Due to these changes and some other experiments in which we could not observe significant NCEs (sometimes only reduced positive compatibility effects, e.g., Bermeitinger \& Hackländer, 2018), we expected at least reduced compatibility effects with longer SOAs compared to the short SOA for horizontal motions. For vertical motions, based on the results of Experiment 1, we similarly expected PCEs at the short SOA and reduced or no PCEs at longer SOAs.

\section{Method}

\section{SUBJECTS}

In total, 59 students from the University of Hildesheim were tested. We had to exclude two subjects due to being outliers regarding their mean error rates (one subject with $>20 \%$ and one subject with $>40 \%$ errors in the horizontal condition; overall both $>15 \%$ errors). Of the remaining subjects, 50 were female, six were male, and one subject indicated being of "other" gender. Forty-nine subjects were righthanded, and eight were left-handed. The median age was 21 years (range: 18-34). Only one subject indicated that they spoke a language with another reading direction than German (i.e., Arabic). However, Arabic-like German-is also read and written in the horizontal orientation (but from right to left). Twenty subjects were assigned to the $150 \mathrm{~ms}$ SOA condition, 20 subjects to the $350 \mathrm{~ms}$ SOA condition, and 17 subjects to the $550 \mathrm{~ms}$ SOA condition. Subjects received $€ 8$ per hour for their participation or participated in exchange for partial course credits.

\section{DESIGN}

A 2 (Orientation: horizontal, vertical) $\times 3$ (Motion direction: direction 1 , direction 2 , neutral) $\times 2$ (Arrow direction: direction 1 , direction 2) $\times 3$ (SOA: $150 \mathrm{~ms}, 350 \mathrm{~ms}, 550 \mathrm{~ms}$ ) design was used. The factor of orientation was varied block-wise within subjects, with the block order counterbalanced across subjects; the factors of motion direction (i.e., prime) and arrow direction (i.e., target) were varied trial-bytrial within subjects; the factor of SOA was varied between subjects. In most previous experiments (e.g., Bermeitinger, 2013; Bermeitinger \& Hackländer, 2018; Bermeitinger \& Kappes, 2018; Bermeitinger \& Wentura, 2016), we used a between-subjects manipulation of SOAs. We already demonstrated that the general pattern with directional motion dot primes, that is, PCEs in short and NCEs in longer SOAs, can also be found when SOA is varied within subjects (Bermeitinger, 2013; Hackländer et al., 2015). However, these effects were less stable and there might have been carry-over effects from one block (or trial) to the next. Additionally, by using vertical as well as horizontal motions (and in the following experiments, questionnaires on reading/writing direction etc.), the experiment was substantially longer compared to our standard experiments (which might result in less motivated subjects over time). Thus, in order to enhance comparison with our previous research and to reduce subjects' frustration, we again used a between-subjects manipulation of SOA.

The focus was again on compatibility of prime and target direction and the corresponding compatibility effects (separately for each orientation).

\section{MATERIALS AND PROCEDURE}

The same stimuli as in Experiment 1 for the vertical orientation were used. For the horizontal orientation, the same materials as in Bermeitinger (2013) were used. That is, the dots moved rightwards or leftwards and the arrows pointed to the right or left (i.e., the whole materials were rotated by $90^{\circ}$ compared to the vertical materials).

The procedure was similar to that of Experiment 1 with the following differences. First, the refresh rate of the monitors was $60 \mathrm{~Hz}$; as a consequence, each screen was presented for $16.66 \mathrm{~ms}$, and the whole prime was presented for $133.33 \mathrm{~ms}$ (i.e., eight refresh cycles). The prime event was followed by a blank screen of $16.66 \mathrm{~ms}$ in the $150 \mathrm{~ms}$ SOA condition, $216.66 \mathrm{~ms}$ in the $350 \mathrm{~ms}$ SOA condition, and 416.66 $\mathrm{ms}$ in the $550 \mathrm{~ms}$ SOA condition.

Second, English instructions were given verbally via headphones. Subjects were instructed to quickly and accurately categorise each arrow with regard to its direction (by pressing the right/left key with their right index finger/right middle finger for right/left arrows, respectively, or the upper/lower key with their right index finger/right thumb for up/down pointing arrows; for right and left arrows, the response keys were the 3 and 1 keys on the numeric pad, on which a right or left arrow was pasted, respectively; for up and down arrows, the response keys were the + and the Enter key on the numeric pad, on which an up or down arrow was pasted, respectively).

Third, each subject worked through four blocks of 36 trials each for the horizontal orientation and four blocks of 36 trials each for the vertical orientation (288 trials in total). Each block consisted of 12 compatible trials (six with dots moving rightwards/leftwards or upwards/downwards, respectively), 12 incompatible trials (six with dots moving rightwards/leftwards or upwards/downwards, respectively), and 12 neutral trials (six with dots moving outwards and inwards, respectively); half of the trials had right or up arrow targets, the other half had left or down arrow targets. There was a short pause after each block. Before the first experimental block of each orientation, there was a practice phase with 12 trials.

Fourth, at the end of the experiment, demographic data, horizontal and vertical reading and writing experience, as well as language skills were assessed with a short paper-and-pencil questionnaire. Results 


\section{TABLE 4.}

Mean Values (SD in Parentheses; Experiments 2 to 4) and Differences Between Samples (Experiments 3 and 4) of Subjects' Reading and Writing Experiences Regarding Horizontal and Vertical Script Orientation.

\begin{tabular}{|c|c|c|c|c|c|c|c|}
\hline & \multirow{2}{*}{$\begin{array}{c}\text { Experiment } 2 \\
\text { German }\end{array}$} & \multicolumn{3}{|c|}{ Experiment 3} & \multicolumn{3}{|c|}{ Experiment 4} \\
\hline & & German & Malaysian & Difference & German & Japanese & Difference \\
\hline Reading direction ${ }^{\mathrm{a}}$ & $8.17(1.69)$ & $8.91(0.34)$ & $7.62(1.87)$ & $p<.001$ & $8.03(1.84)$ & $5.92(2.27)$ & $p<.001$ \\
\hline Writing direction ${ }^{\mathrm{a}}$ & $8.27(1.74)$ & $8.94(0.23)$ & $8.25(1.84)$ & $p=.001$ & $8.11(1.77)$ & $7.76(1.79)$ & $p=.404$ \\
\hline $\begin{array}{l}\text { Time per week reading/writing } \\
\text { horizontally (in hours) }\end{array}$ & $21.36(16.3)$ & $20.63(15.8)$ & $23.93(18.0)$ & $p<.001$ & $22.75(18.4)$ & $23.80(12.0)$ & $p=.778$ \\
\hline $\begin{array}{l}\text { Time per week reading/writing vertically } \\
\text { (in hours) }\end{array}$ & $0.02(0.15) \#$ & $0.00(0.00) \#$ & $4.91(7.89)$ & $p<.001$ & $0.00(0.00) \#$ & $8.64(8.47)$ & $p<.001$ \\
\hline $\begin{array}{l}\text { I feel more comfortable reading vertically } \\
\text { than horizontally }\end{array}$ & $4.25(1.15)$ & $4.77(0.45)$ & $3.66(1.00)$ & $p<.001$ & $\sim$ & $3.16(1.39)$ & l \\
\hline $\begin{array}{l}\text { I feel more comfortable writing vertically } \\
\text { than horizontally }\end{array}$ & $4.37(1.11)$ & $4.84(0.37)$ & $3.94(1.10)$ & $p<.001$ & $\sim$ & $3.92(1.28)$ & I \\
\hline $\begin{array}{l}\text { I feel more comfortable reading } \\
\text { horizontally than vertically }\end{array}$ & $1.46(0.97)$ & $1.08(0.27)$ & $1.56(0.89)$ & $p<.001$ & $\sim$ & $2.18(1.25)$ & I \\
\hline $\begin{array}{l}\text { I feel more comfortable writing } \\
\text { horizontally than vertically }\end{array}$ & $1.51(1.09)$ & $1.09(0.29)$ & $1.52(0.91)$ & $p<.001$ & $\sim$ & $1.82(1.18)$ & I \\
\hline
\end{tabular}

Note. ${ }^{\text {a }} 1$ = always vertically; 5 = vertically and horizontally equally frequent; $9=$ always horizontally; ${ }^{\mathrm{b}} 1=$ absolutely agree; $5=$ absolutely disagree; ${ }^{*}=$ Hours were only counted if subjects indicated speaking at least one language which can be written/read vertically' $\sim$ Data were not valid due to instruction errors for this question in the German sample in Experiment 4

of the questionnaire for reading/writing experience can be found in Table 4 (for this and the following experiments).

Fifth, before the response priming experiment, some subjects participated in an unrelated study with a colour classification task.

\section{Results}

Following to the same outlier and error criteria as in Experiment 1, separately for vertical and horizontal trials, $6.19 \%$ of all trials had to be excluded (2.32\% of all due to errors) from the RT analyses. For all following analyses, if necessary (i.e., if the Mauchly's test of sphericity was significant), Greenhouse-Geisser corrected $F, p$, and $\eta_{\mathrm{p}}{ }^{2}$ values were reported. Mean RTs and error rates are given in Table 5, and mean RT compatibility effects for each condition are shown in Figure 3.

\section{REACTION TIMES}

Mean RTs were examined with a repeated-measures ANOVA with the within-subjects factors of orientation (horizontal and vertical) and compatibility (compatible, incompatible, neutral) and the between-subjects factor of SOA (150 ms, $350 \mathrm{~ms}, 550 \mathrm{~ms})$; adding the order of orientation as a factor, there were no significant effects including this factor (all $p s>.08$ ), indicating that no order effects were present in the experiment. The main effect of SOA was significant, $F(2,54)=3.47, p=.038, \eta_{\mathrm{p}}{ }^{2}=.114$, indicating faster responses in the $550 \mathrm{~ms} \mathrm{SOA}$ condition compared to the $150 \mathrm{~ms}$ SOA condition (post-hoc test with Bonferroni correction, $p=.034$; RTs in the $550 \mathrm{~ms}$ and $350 \mathrm{~ms} \mathrm{SOA}$ condition as well as in the $150 \mathrm{~ms}$ and $350 \mathrm{~ms} \mathrm{SOA}$ condition did not differ significantly, $p s>.32$ ). The main effect of orientation was also significant, $F(1,54)=92.33, p<.001, \eta_{\mathrm{p}}{ }^{2}=.631$, indicating faster responses in the horizontal compared to the vertical condition. Furthermore, there was a significant main effect of com- patibility, $F(2,108)=17.97, p<.001, \eta_{\mathrm{p}}{ }^{2}=.250$; repeated contrasts showed significant differences between incompatible and neutral trials $(p<.001)$ as well as between neutral and compatible trials $(p=$ .015). Most interestingly, this main effect was qualified by a significant interaction of compatibility and SOA, $F(4,108)=6.89, p<.001, \eta_{\mathrm{p}}{ }^{2}$ $=.203$ (there were no additional significant interactions, all $p s>.26$ ).

Therefore, we analysed the compatibility effects (for the sake of completeness for the horizontal as well as the vertical orientation) for each SOA separately. In the $150 \mathrm{~ms} \mathrm{SOA}$ condition, there was a significant compatibility effect in the horizontal orientation, $t(19)=$ $6.02, p<.001$, as well as the vertical orientation, $t(19)=5.12, p<.001$. In the $350 \mathrm{~ms}$ as well as the $550 \mathrm{~ms}$ SOA condition, there were no significant compatibility effects with any orientation, all $p s>.13$. In each SOA condition, differences between the compatibility effects in the horizontal and vertical orientations were not significant (all $p s>.11$ ).

\section{ERROR RATES}

A similar ANOVA with the factors of orientation, compatibility, and SOA for error rates revealed a significant main effect of compatibility, $F(2,108)=6.97, p=.002, \eta_{\mathrm{p}}{ }^{2}=.114$, which was qualified by a significant interaction of Compatibility and SOA, $F(4,108)=4.08, p=$ $.004, \eta_{\mathrm{p}}{ }^{2}=.131$. All other main or interaction effects were not significant, all $p s>.09$. In the $150 \mathrm{~ms}$ SOA condition, there were significant compatibility effects for the horizontal orientation, $t(19)=2.98, p=$ .008 , as well as the vertical orientation, $t(19)=2.40, p=.027$. In the other SOA conditions, there was only a significant compatibility effect for the vertical orientation in the $550 \mathrm{~ms}$ SOA condition, $t(16)$ $=2.38, p=.030$ (all other compatibility effects were not significant, all $p s>.48)$ 


\section{TABLE 5.}

Mean Response Times (SD in Parentheses) and Mean Error Rates (SD in Parentheses) of the Compatible, Incompatible, and Neutral Conditions for Each Stimulus Onset Asynchrony $(150$ ms, 350 ms, 550 ms) and Each Orientation (Horizontal, Vertical) Condition of Experiment 2.

\begin{tabular}{|c|c|c|c|c|c|c|c|c|c|c|c|c|}
\hline & \multicolumn{6}{|c|}{ Horizontal orientation } & \multicolumn{6}{|c|}{ Vertical orientation } \\
\hline & \multicolumn{3}{|c|}{ Response times (in ms) } & \multicolumn{3}{|c|}{ Error rates (in \%) } & \multicolumn{3}{|c|}{ Response times (in ms) } & \multicolumn{3}{|c|}{ Error rates (in \%) } \\
\hline & Compatible & Incompatible & Neutral & Compatible & Incompatible & Neutral & Compatible & Incompatible & Neutral & Compatible & Incompatible & Neutral \\
\hline $150 \mathrm{~ms}$ & 366 & 355 & 342 & 0.73 & 3.02 & 2.71 & 361 & 377 & 365 & 1.15 & 3.44 & 2.40 \\
\hline SOA & $(29.42)$ & $(24.03)$ & $(27.38)$ & $(1.40)$ & $(4.19)$ & $(2.80)$ & $(33.15)$ & $(34.02)$ & $(30.51)$ & $(2.08)$ & $(5.38)$ & $(2.27)$ \\
\hline $350 \mathrm{~ms}$ & 334 & 336 & 334 & 3.65 & 3.02 & 2.08 & 352 & 360 & 357 & 2.60 & 3.13 & 2.19 \\
\hline SOA & $(34.30)$ & $(40.13)$ & $(34.84)$ & $(4.16)$ & (3.48) & $(2.79)$ & $(34.26)$ & $(38.79)$ & (38.49) & $(3.50)$ & $(3.97)$ & (2.48) \\
\hline $550 \mathrm{~ms}$ & 321 & 319 & 319 & 2.33 & 2.33 & 1.10 & 334 & 339 & 339 & 2.21 & 3.92 & 2.45 \\
\hline SOA & $(30.73)$ & (30.98) & $(28.96)$ & $(2.74)$ & $(2.07)$ & (1.49) & $(38.09)$ & (35.12) & $(38.60)$ & $(2.01)$ & (3.37) & (3.47) \\
\hline
\end{tabular}

Note. ${ }^{\mathrm{a}} 1$ = always vertically; 5 = vertically and horizontally equally frequent; $9=$ always horizontally; ${ }^{\mathrm{b}} 1=$ absolutely agree; $5=$ absolutely disagree; ${ }^{*}=$ Hours were only counted if subjects indicated speaking at least one language which can be written/read vertically' $\sim$ Data were not valid due to instruction errors for this question in the German sample in Experiment 4.

\section{Discussion}

The second experiment compared the effect of horizontal and vertical motion primes in a follow-up experiment with German subjects. The subjects responded overall faster to trials in which the motion primes were horizontal, but there was no interaction between orientation and compatibility. The difference between compatible trials and incompatible trials was not larger for horizontal motion primes.

However, there was an interaction between compatibility and SOA. Mirroring Experiment 1 with vertical motion primes and some previous findings with horizontal motion primes (e.g., Bermeitinger, 2013; Bermeitinger \& Wentura, 2016), both directions showed a decrease in compatibility effects as the time between the prime and target increased. For the horizontal motions, we observed a PCE at the shortest SOA of $150 \mathrm{~ms}$, but this response advantage disappeared at longer SOAs of 350 and $550 \mathrm{~ms}$. For the vertical motions, we observed PCEs at every SOA, but this response advantage was smaller at longer SOAs.

It might seem unexpected that we did not find significant NCEs even with horizontal materials, but, as already presented above, there are some previous findings showing that NCEs are not always present or significant at longer SOAs (e.g., Bermeitinger \& Hackländer, 2018). However, the general pattern with the interaction of compatibility and SOA-and sharply reduced effects at longer SOAs-was clearly obvious and seems reliable. On the other hand, we made some changes (e.g., the presentation durations) that also could have led to the absence of NCEs at longer SOAs.

Overall, we can conclude that response priming with horizontal as well as vertical motion primes and the given changes (i.e., 60 instead of $75 \mathrm{~Hz}$, English instructions, response with one hand) is working, and that we could use the task for the subsequent experiments comparing subjects from different countries to investigate the influence of culturally embedded habits regarding reading/writing orientation and perceptual preferences.

\section{EXPERIMENT 3}

In Experiment 3, we used vertical and horizontal motions as primes in four SOA conditions (150 ms, $350 \mathrm{~ms}, 550 \mathrm{~ms}$, and $750 \mathrm{~ms})$. The longest SOA of $750 \mathrm{~ms}$ was added to better capture the time course of compatibility effects. Additionally, we never used this SOA with row-of-dots primes before and wanted to investigate the further development of PCEs or NCEs. Further, we did not find any NCEs with vertical motions and no NCEs with flatscreens up to an SOA of 550 $\mathrm{ms}$ (see the experiments above). Therefore, we wanted to use an even longer SOA in order to make it even more probable to find an NCE. We tested subjects from Germany and Malaysia to investigate samples that differed in their reading and writing experiences. In Malaysia, there are three common ethnicities. Whereas the majority is Malay, there are substantial minorities of Malaysians with either a Chinese or an Indian background. Chinese Malaysians are typically confronted also with Mandarin, Cantonese and/or Hokkien language. These Chinese languages can be written in a vertical orientation.

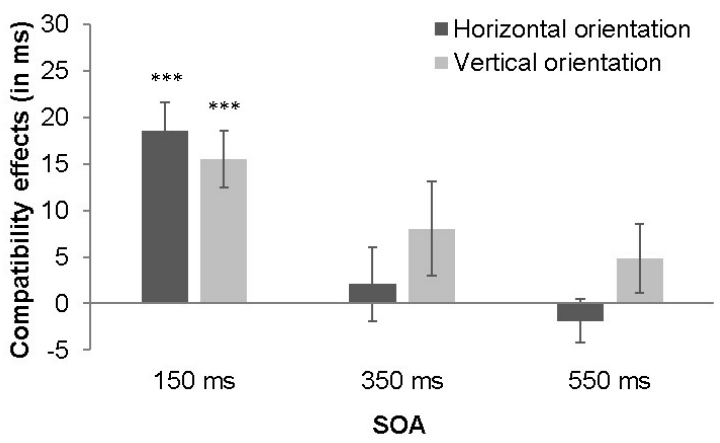

FIGURE 3.

Mean RT compatibility effects (mean RT incompatible-mean RT compatible) from the 150, 350, and 550 ms SOA condition in Experiment 2 (with a German sample), separately depicted for the horizontal and vertical orientation; error bars represent the standard error of the mean $( \pm \mathrm{SE}) ;{ }^{* *} p<.001$ 
TABLE 6.

Mean Response Times (SD in Parentheses) and Mean Error Rates (SD in Parentheses) of the Compatible, Incompatible, and Neutral Conditions for Each Country (Germany, Malaysia), Each Stimulus Onset Asynchrony (150 ms, 350 ms, 550 ms, 750 ms) and Each Orientation (Horizontal, Vertical) Condition of Experiment 3.

\begin{tabular}{|c|c|c|c|c|c|c|c|c|c|c|c|c|}
\hline \multirow[b]{3}{*}{ Germany } & \multicolumn{6}{|c|}{ Horizontal orientation } & \multicolumn{6}{|c|}{ Vertical orientation } \\
\hline & \multicolumn{3}{|c|}{ Response times (in ms) } & \multicolumn{3}{|c|}{ Error rates (in \%) } & \multicolumn{3}{|c|}{ Response times (in ms) } & \multicolumn{3}{|c|}{ Error rates (in \%) } \\
\hline & Compatible & Incompatible & Neutral & Compatible & Incompatible & Neutral & Compatible & Incompatible & Neutral & Compatible & Incompatible & Neutral \\
\hline $150 \mathrm{~ms}$ & 353 & 374 & 358 & 1.29 & 1.88 & 1.09 & 360 & 377 & 365 & 1.49 & 2.28 & 1.59 \\
\hline SOA & $(36.00)$ & $(33.88)$ & $(32.04)$ & $(2.42)$ & $(2.07)$ & $(1.69)$ & (30.99) & $(31.54)$ & $(30.35)$ & $(2.39)$ & $(2.79)$ & $(2.37)$ \\
\hline $350 \mathrm{~ms}$ & 333 & 335 & 334 & 2.08 & 2.81 & 1.88 & 345 & 350 & 351 & 2.40 & 2.08 & 2.29 \\
\hline SOA & $(29.49)$ & $(30.06)$ & $(31.02)$ & $(2.53)$ & $(2.97)$ & $(2.61)$ & $(22.98)$ & $(25.64)$ & $(28.17)$ & $(2.89)$ & $(2.44)$ & $(2.13)$ \\
\hline $550 \mathrm{~ms}$ & 344 & 344 & 343 & 0.77 & 1.21 & 1.43 & 354 & 353 & 354 & 1.64 & 1.97 & 1.32 \\
\hline SOA & $(44.67)$ & $(44.96)$ & $(44.67)$ & $(1.24)$ & $(2.44)$ & $(2.20)$ & $(44.66)$ & $(45.51)$ & (44.88) & $(2.36)$ & $(2.83)$ & (1.86) \\
\hline $750 \mathrm{~ms}$ & 339 & 342 & 341 & 1.04 & 1.98 & 1.98 & 356 & 362 & 357 & 1.88 & 1.88 & 1.15 \\
\hline SOA & $(31.35)$ & $(33.10)$ & $(33.63)$ & $(1.59)$ & $(1.97)$ & $(1.85)$ & $(39.32)$ & $(36.08)$ & $(38.83)$ & $(2.02)$ & $(2.33)$ & $(1.72)$ \\
\hline Malaysia & Compatible & Incompatible & Neutral & Compatible & Incompatible & Neutral & Compatible & Incompatible & Neutral & Compatible & Incompatible & Neutral \\
\hline $150 \mathrm{~ms}$ & 349 & 369 & 359 & 1.04 & 2.18 & 1.70 & 381 & 399 & 389 & 1.23 & 2.75 & 1.80 \\
\hline SOA & $(44.87)$ & $(37.61)$ & $(42.34)$ & $(1.67)$ & (3.18) & $(2.70)$ & (51.43) & $(46.10)$ & (51.38) & $(2.00)$ & $(4.19)$ & $(2.75)$ \\
\hline $350 \mathrm{~ms}$ & 324 & 334 & 329 & 0.82 & 1.36 & 0.91 & 343 & 348 & 347 & 1.00 & 1.27 & 1.00 \\
\hline SOA & $(30.75)$ & $(36.07)$ & $(32.72)$ & $(1.37)$ & $(2.85)$ & $(1.52)$ & (33.19) & (33.19) & (30.59) & $(1.24)$ & $(1.96)$ & $(1.76)$ \\
\hline $550 \mathrm{~ms}$ & 344 & 342 & 336 & 0.85 & 0.57 & 0.66 & 361 & 366 & 362 & 0.95 & 1.04 & 0.76 \\
\hline SOA & $(37.29)$ & (35.05) & (32.09) & (1.53) & $(0.95)$ & (1.49) & (41.84) & $(40.70)$ & (36.05) & $(1.40)$ & (1.79) & (1.03) \\
\hline $750 \mathrm{~ms}$ & 343 & 348 & 344 & 0.66 & 0.95 & 0.66 & 371 & 380 & 379 & 1.04 & 1.33 & 0.85 \\
\hline SOA & (41.29) & $(41.22)$ & (40.94) & $(1.35)$ & $(2.01)$ & (1.18) & (49.17) & (49.49) & $(50.07)$ & $(1.40)$ & (1.64) & (1.39) \\
\hline
\end{tabular}

Thus, we examined whether compatibility effects are influenced by reading/writing experiences, especially whether compatibility effects with vertically oriented materials differ between the German and Chinese Malaysian sample. Besides smaller PCEs at longer SOAs, we expected the following pattern: More reading/writing experiences with the vertical orientation in the Chinese Malaysian sample should led to overall faster processing of vertical stimuli and to more pronounced pre-activations of corresponding responses. Thus, overall, Malaysian subjects might show larger compatibility effects with vertical materials than German subjects (or at least an altered relative difference between vertical and horizontal compatibility effects compared to German subjects).

\section{Method}

\section{SUBJECTS}

Eighty students from the University of Hildesheim, Germany (66 female, 14 male; 66 right-handed, 11 left-handed, three with no handedness dominance; median age $=22$ years, range: $19-52 ;$ nSOA $150 \mathrm{~ms}$ $=21, \mathrm{nSOA} 350 \mathrm{~ms}=20$, nSOA $550 \mathrm{~ms}=19$, nSOA $750 \mathrm{~ms}=20$ ), as well as 89 students with a Chinese background from the University of Nottingham Malaysia, Malaysia (56 female, 33 male; 78 right-handed, 11 left-handed; median age $=21$ years, range: 18 to 29 ; $\mathrm{nSOA} 150 \mathrm{~ms}$ $=22, \mathrm{nSOA} 350 \mathrm{~ms}=23, \mathrm{nSOA} 550 \mathrm{~ms}=22$, nSOA $750 \mathrm{~ms}=22$ ), were tested for this experiment. German subjects received either $€ 6$
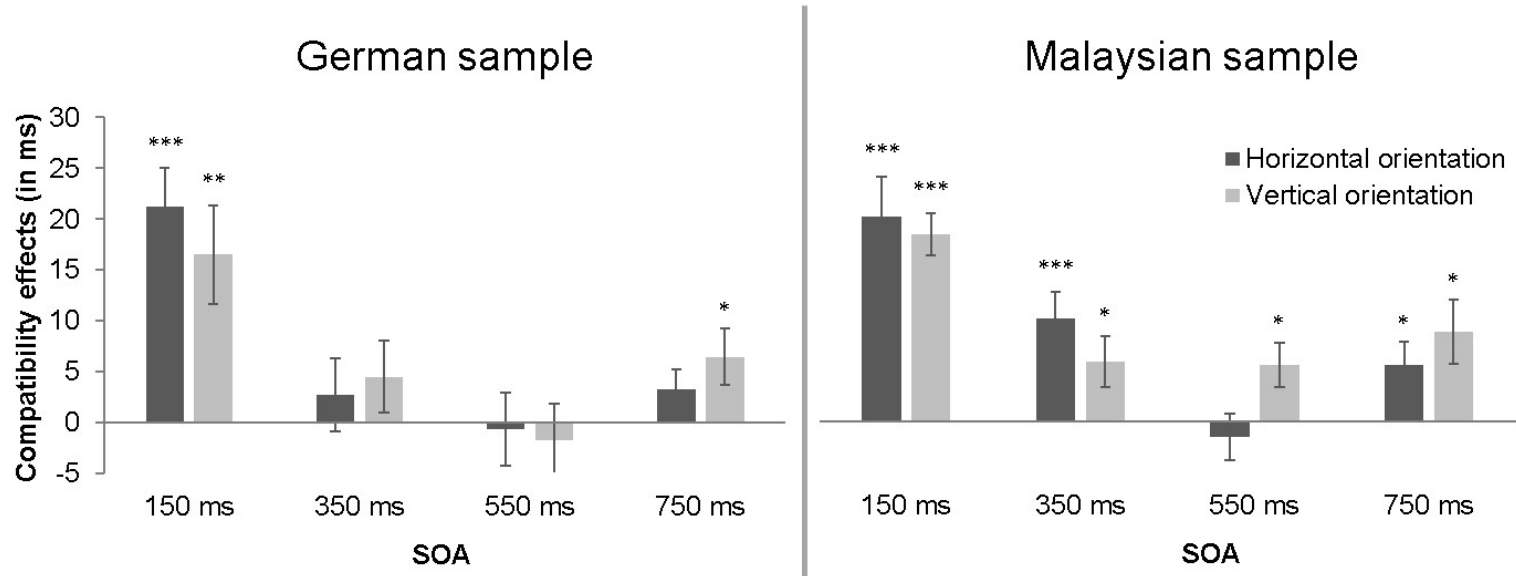

\section{FIGURE 4.}

Mean RT compatibility effects (mean RT incompatible - mean RT compatible) from the 150, 350, 550, and 750 ms SOA conditions in Experiment 3 for the German and Chinese Malaysian sample, separately depicted for the horizontal and vertical orientation; error bars represent the standard error of the mean $( \pm \mathrm{SE}) ;{ }^{* * *} p<.001,{ }^{* *} p<.01,{ }^{*} p<.05$ 
Euro or partial course credits for their participation, whereas Malaysian subjects received RM5. Originally, we tested more subjects, who were not included here, as their experiment was ran with $50 \mathrm{~Hz}$ refresh rate instead of $60 \mathrm{~Hz}$. These subjects were included in another experiment in which we used $50 \mathrm{~Hz}$ for all subjects.

Only five German subjects indicated that they spoke any language with another reading direction than German (three subjects spoke a language with horizontal orientation from right to left: two Arabic and one Farsi; only two subjects spoke a language that is or can be vertically oriented: one Chinese and one Vietnamese). Only three Chinese Malaysian subjects indicated not speaking any language that is or can be written in a vertical orientation. However, 25 Chinese Malaysian subjects never read/wrote in vertical orientation in their daily life. All Chinese Malaysian subjects spoke at least one language exclusively written in horizontal orientation (most often English and/or Malay).

\section{DESIGN, MATERIAL, AND PROCEDURE}

The same design, materials, and procedure were used as in Experiment 2, with the following changes. First, the factor of country (Germany, Malaysia) was added. Second, the factor of SOA now was varied on four levels: $150 \mathrm{~ms}, 350 \mathrm{~ms}, 550 \mathrm{~ms}$, and $750 \mathrm{~ms}$. Third, we used either laptop or desktop computers for the German versus Malaysian sample, respectively, both with flat screen monitors. German subjects were tested either in the laboratory or at other areas in the university, whereas Malaysian subjects were tested in the laboratory. Additionally, to prevent further priming of a left-right oriented reading, all keys of the keyboard with the exception of the response keys were covered with white paper or tape.

\section{Results}

The same error and outlier criteria were applied as in the previous experiments. Due to these criteria, $5.66 \%$ of all trials had to be excluded ( $1.42 \%$ of all due to errors) from the RT analyses. For all following analyses, if necessary (i.e., if the Mauchly's test of sphericity was significant), Greenhouse-Geisser corrected $F, p$, and $\eta_{p}^{2}$ values are reported. Mean RTs and error rates are given in Table 6 , and mean RT compatibility effects for each condition are shown in Figure 4.

\section{REACTION TIMES}

Mean RTs were subjected to a repeated-measures ANOVA with within-subjects factors of orientation (horizontal, vertical) and compatibility (compatible, incompatible, neutral), and between-subjects factors of SOA (150 ms, $350 \mathrm{~ms}, 550 \mathrm{~ms}, 750 \mathrm{~ms}$ ) and country (Germany, Malaysia). Adding the order of orientation as a factor, there were two significant interactions: orientation $\times$ compatibility $\times$ order of orientation, $F(2,306)=5.75, p=.004, \eta_{p}^{2}=.036$, and orientation $\times$ compatibility $\times$ SOA $\times$ order of orientation, $F(6,306)=2.79, p=.013, \eta_{p}{ }^{2}=.052$ (all other effects including order of orientation were not significant, $p$ s $>$.16).

The main effect of SOA was significant, $F(3,161)=4.98, p=.002$, $\eta_{\mathrm{p}}{ }^{2}=.085$, indicating faster responses in the $150 \mathrm{~ms}$ SOA condition compared to the $350 \mathrm{~ms}$ SOA condition (post-hoc test with Bonferroni correction, $p=.001$; all other SOA conditions did not differ significantly, $p s>.10)$. Furthermore, the main effect of orientation was significant, $F(1,161)=159.11, p<.001, \eta_{\mathrm{p}}{ }^{2}=.497$, indicating faster responses in the horizontal compared to the vertical condition. There was also a significant main effect of compatibility, $F(2,322)=55.59, p<.001, \eta_{\mathrm{p}}{ }^{2}=.257$; repeated contrasts showed significant differences between incompatible and neutral trials $(p<.001)$ as well as between neutral and compatible trials $(p<.001)$. These main effects were qualified by significant interactions of orientation and country, $F(1,161)=20.28, p<.001, \eta_{p}{ }^{2}=$ .112 (indicating a larger RT difference between horizontal and vertical oriented materials in the Malaysian sample compared to the German sample), as well as of compatibility and SOA, $F(6,322)=15.02, p<.001$, $\eta_{\mathrm{p}}{ }^{2}=.219$, and by an almost significant interaction of orientation, country, and SOA, $F(3,161)=2.58, p=.055, \eta_{p}{ }^{2}=.046$. The main effect of country and all other interaction effects were not significant, all $p s>.13$.

Thus, we analysed the compatibility effects further with a univariate ANOVA with the between-subjects factor of SOA. The analyses revealed a significant intercept, $F(1,165)=74.89, p<.001, \eta_{\mathrm{p}}{ }^{2}=.312$ (indicating overall a significant compatibility effect with faster responses in compatible than incompatible trials) and a significant main effect of SOA, $F(3$, $165)=18.64, p<.001, \eta_{\mathrm{p}}{ }^{2}=.253$. Post-hoc tests (multiple comparisons) showed that the compatibility effect in the $150 \mathrm{~ms}$ SOA condition differed from the compatibility effects in the other SOA conditions (all $p s<$ .001 ), and that all other compatibility effects did not differ significantly (all $p s>.21$ ).

\section{ERROR RATES}

The same ANOVA with the factors of orientation, compatibility, SOA, and Country for error rates revealed a significant main effect of orientation, $F(1,161)=5.75, p=.018, \eta_{\mathrm{p}}{ }^{2}=.034$ (indicating more errors for vertically than horizontally oriented materials), a significant main effect of compatibility, $F(2,322)=5.74, p=.005, \eta_{p}{ }^{2}=.034$ (repeated contrasts showed significant differences between incompatible and neutral trials, $p=.011$, but not between neutral and compatible trials, $p=.65)$, and a significant main effect of country, $F(1,116)=7.07, p=$ $.009, \eta_{\mathrm{p}}{ }^{2}=.042$ (indicating less errors in the Malaysian than the German sample). The main effect of SOA and all other interaction effects were not significant, all $p s>.16$.

\section{Discussion}

In Experiment 3, we compared Malaysian and German subjects in four different SOA levels with horizontal as well as vertical motion primes in a response priming experiment. We found no significant differences in compatibility effects between the vertical and horizontal orientation, and between samples (with numerically larger PCEs in SOAs of $350 \mathrm{~ms}$, $550 \mathrm{~ms}$, and $750 \mathrm{~ms}$ in the Malaysian sample). However, we found strong differences between the shortest (i.e., $150 \mathrm{~ms}$ ) and longer (i.e., $350 \mathrm{~ms}$, $550 \mathrm{~ms}, 750 \mathrm{~ms}$ ) SOA conditions: Subjects showed large PCEs in the short SOA, and smaller or no compatibility effects in the longer SOA conditions.

The general pattern in this experiment seems to be highly comparable to the typical pattern-PCEs at short SOAs and sharply reduced 


\section{TABLE 7.}

Mean Response Times (SD in Parentheses) and Mean Error Rates (SD in Parentheses) of the Compatible, Incompatible, and Neutral Conditions for Each Country (Germany, Japan), Each Stimulus Onset Asynchrony (150 ms, 350 ms) and Each Orientation (Horizontal, Vertical) Condition of Experiment 4.

\begin{tabular}{|c|c|c|c|c|c|c|c|c|c|c|c|c|}
\hline \multirow[b]{3}{*}{ Germany } & \multicolumn{6}{|c|}{ Horizontal orientation } & \multicolumn{6}{|c|}{ Vertical orientation } \\
\hline & \multicolumn{3}{|c|}{ Response times (in ms) } & \multicolumn{3}{|c|}{ Error rates (in \%) } & \multicolumn{3}{|c|}{ Response times (in ms) } & \multicolumn{3}{|c|}{ Error rates (in \%) } \\
\hline & Compatible & Incompatible & Neutral & Compatible & Incompatible & Neutral & Compatible & Incompatible & Neutral & Compatible & Incompatible & Neutral \\
\hline $150 \mathrm{~ms}$ & 331 & 355 & 342 & 1.15 & 4.38 & 1.15 & 352 & 368 & 354 & 1.56 & 4.06 & 2.19 \\
\hline SOA & $(31.37)$ & $(28.37)$ & $(29.98)$ & $(1.58)$ & (3.94) & $(1.43)$ & $(41.32)$ & (38.28) & $(36.25)$ & $(2.12)$ & $(3.79)$ & $(3.06)$ \\
\hline $350 \mathrm{~ms}$ & 338 & 349 & 344 & 2.47 & 2.99 & 2.21 & 353 & 363 & 352 & 2.73 & 3.26 & 2.99 \\
\hline SOA & $(29.56)$ & $(37.13)$ & $(21.23)$ & $(2.43)$ & $(3.40)$ & $(1.93)$ & $(36.28)$ & $(34.02)$ & $(33.27)$ & $(1.82)$ & $(3.57)$ & $(2.28)$ \\
\hline Japan & Compatible & Incompatible & Neutral & Compatible & Incompatible & Neutral & Compatible & Incompatible & Neutral & Compatible & Incompatible & Neutral \\
\hline $150 \mathrm{~ms}$ & 326 & 347 & 332 & 1.25 & 3.96 & 1.77 & 357 & 369 & 359 & 1.88 & 2.81 & 2.71 \\
\hline SOA & $(50.67)$ & $(54.21)$ & (55.40) & (1.96) & $(4.27)$ & $(2.06)$ & $(82.72)$ & $(74.32)$ & (77.58) & (2.13) & $(2.17)$ & (3.25) \\
\hline $350 \mathrm{~ms}$ & 334 & 347 & 338 & 1.16 & 2.20 & 0.93 & 341 & 360 & 355 & 0.93 & 1.97 & 1.50 \\
\hline SOA & $(29.94)$ & (29.43) & (26.98) & (1.28) & (3.39) & (1.47) & (30.35) & (33.04) & (30.83) & (1.63) & $(2.42)$ & (1.86) \\
\hline
\end{tabular}

(or even negative) compatibility effects at longer SOAs-found in Experiments 1 and 2 as well as in previous work (e.g., Bermeitinger, 2013; Bermeitinger \& Hackländer, 2018; Bermeitinger \& Wentura, 2016), without significant differences between German and Malaysian subjects. When looking at the simple effects, it is, however, remarkable that Malaysian subjects showed in seven out of eight cases significant PCEs, whereas the German sample had significant compatibility effects in only three out of eight cases. Before we discuss the results of Experiment 3 in more detail, we first test another sample (Experiment 4) and then conduct a combined analysis.

\section{EXPERIMENT 4}

In Experiment 4, we tested a sample from another country in which vertically reading/writing orientation is even more present than in Malaysia. Thus, in Experiment 4, we contrasted a German sample with a sample from Japan. Again, we used vertical and horizontal motions as primes, now in two different SOA conditions (150 ms and $350 \mathrm{~ms}$ ). Because we did not find compatibility effects at longer SOAs $(550 \mathrm{~ms}$ and $750 \mathrm{~ms}$ ), we did not include these SOA conditions in Experiment 4 and fewer subjects were needed. Due to more reading/writing experiences in the vertical direction, we expected larger pre-activations (and thus compatibility effects) with vertical materials in Japanese compared to German subjects).

\section{Method}

\section{SUBJECTS}

Thirty-eight students from the University of Hildesheim, Germany, participated in the experiment (two further subjects aborted the experiment because they recognised their previous participation in a similar experiment). We had to exclude two subjects due to being outliers regarding their mean error rates (> 10\% errors). There were 36 remain-

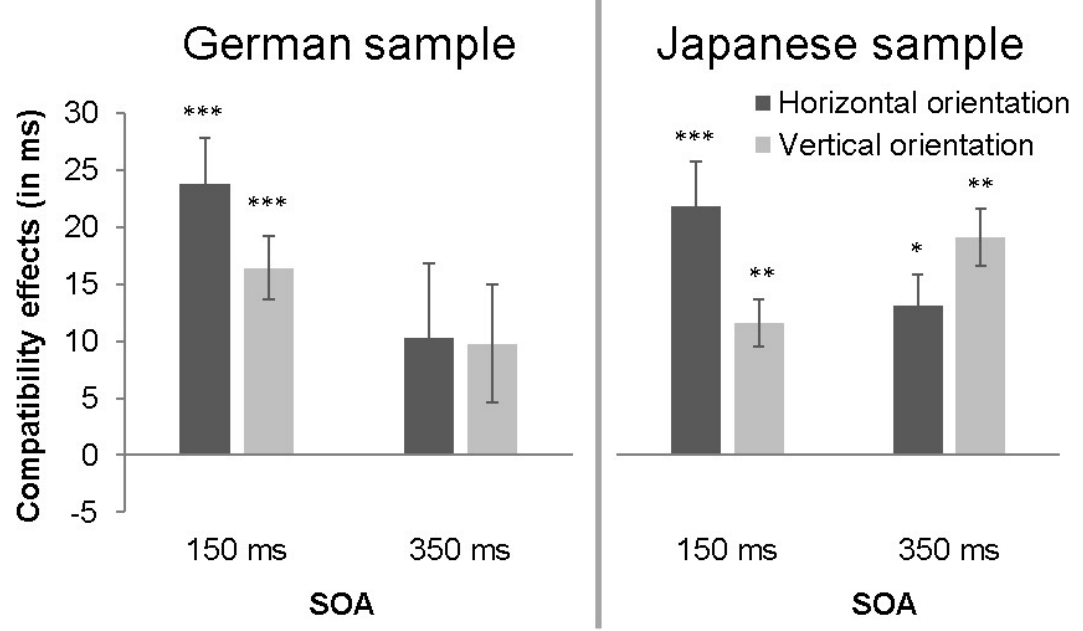

FIGURE 5.

Mean RT compatibility effects (mean RT incompatible-mean RT compatible) from the 150 and 350 ms Stimulus onset asynchrony conditions in Experiment 4 for the German and Japanese sample, separately depicted for the horizontal and vertical orientation; error bars represent the standard error of the mean $( \pm \mathrm{SE}) ;{ }^{* * *} p<.001,{ }^{* *} p<.01,{ }^{*} p<.05$ 
ing subjects in the German sample (29 female, five male, one "other" gender, one missing value; 32 right-handed, 3 left-handed, one with no handedness dominance; median age $=20$ years, range: $18-52 ;$ nSOA 150 $\mathrm{ms}=20, \mathrm{nSOA} 350 \mathrm{~ms}=16$ ).

Forty-three students from the Dokkyo University, Tokyo, Japan, were also tested for this experiment. We had to exclude two subjects due to technical problems during data recording and three subjects due to being outliers regarding their mean error rates (> 10\% errors). There were 38 remaining subjects in the Japanese sample ( 25 female, 13 male; all right-handed; median age $=20$ years, range: $18-43$; nSOA $150 \mathrm{~ms}=$ 20, nSOA $350 \mathrm{~ms}=18$ ).

Only one German subject indicated that they spoke any language with another reading direction than German (i.e., Arabic, with a horizontal orientation from right to left). Only four Japanese subjects indicated that they never read/write in vertical orientation in their daily life; all Japanese subjects indicated that they spoke at least one language that is written in a horizontal orientation (most often English and/or German). German subjects received partial course credits for their participation, whereas Japanese subjects received a small present.

\section{DESIGN, MATERIAL, AND PROCEDURE}

The same design, materials, and procedure were used as in Experiment 3, with the following changes. First, we tested German versus Japanese subjects. Second, the factor of SOA now was varied on two levels: $150 \mathrm{~ms}$ and $350 \mathrm{~ms}$. Third, we used the same laptop computers for the German and the Japanese samples. The German subjects were tested either in the laboratory or in seminar rooms or waiting areas at the university; the Japanese subjects were tested outside the laboratory in either seminar rooms or waiting areas at the university.

\section{Results}

The same error and outlier criteria were applied as in the previous experiments. Due to these criteria, $6.41 \%$ of all trials had to be excluded (2.25\% of all due to errors) from the RT analyses. For all following analyses, if necessary (i.e., if the Mauchly's test of sphericity was significant), Greenhouse-Geisser corrected $F, p$, and $\eta_{p}{ }^{2}$ values are reported. Mean RTs and error rates are given in Table 7, and mean RT compatibility effects for each condition are shown in Figure 5.

\section{REACTION TIME}

Mean RTs were examined with a repeated-measures ANOVA with the within-subjects factors of orientation (horizontal, vertical) and compatibility (compatible, incompatible, neutral), and the betweensubjects factors of SOA (150 ms, $350 \mathrm{~ms}$ ) and Country (Germany, Japan). Adding the Order of orientation as a factor, there were three significant interactions: compatibility $\times$ order of orientation, $F(2,132)$ $=6.00, p=.010, \eta_{\mathrm{p}}{ }^{2}=.083$, orientation $\times$ compatibility $\times$ order of orientation, $F(2,132)=5.87, p=.011, \eta_{\mathrm{p}}{ }^{2}=.082$, and compatibility $\times$ SOA $\times$ country $\times$ order of orientation, $F(2,132)=7.154, p=.002, \eta_{p}{ }^{2}=.098$ (all other effects including order of orientation were not significant, ps > .08).
The main effect of orientation was significant, $F(1,70)=46.17, p<$ $.001, \eta_{\mathrm{p}}{ }^{2}=.397$, indicating faster responses in the horizontal compared to the vertical condition. Additionally, there was a significant main effect of compatibility, $F(2,140)=59.48, p<.001, \eta_{p}{ }^{2}=.459$; repeated contrasts showed significant differences between incompatible and neutral trials $(p<.001)$ as well as between neutral and compatible trials $(p<.001)$. These main effects were qualified by a significant interaction of orientation, compatibility, and SOA, $F(2,140)=3.87, p=.023, \eta_{\mathrm{p}}{ }^{2}=$ .052 , and by an almost significant interaction of orientation, compatibility, and country, $F(2,140)=2.83, p=.073, \eta_{\mathrm{p}}{ }^{2}=.039$. The main effects of SOA and country and all other interaction effects were not significant, $p s>.11$.

To clarify these interactions, we conducted separate ANOVAs with the factors of orientation and country for each SOA with compatibility effects as the dependent variable. For the $150 \mathrm{~ms}$ SOA condition, there was a significant intercept, $F(1,38)=80.44, p<.001, \eta_{\mathrm{p}}{ }^{2}=.679$, indicating an overall, significant compatibility effect with faster responses in compatible than incompatible trials; the horizontal as well as the vertical compatibility effect were significant, $t(39)=7.97, p<.001$, and $t(39)$ $=5.98, p<.001$, respectively. Furthermore, there was a significant main effect of orientation, $F(1,38)=7.16, p=.011, \eta_{p}{ }^{2}=.159$, indicating a larger horizontal than vertical compatibility effect. All other effects were not significant, $p>.40$. For the $350 \mathrm{~ms}$ SOA condition, there was only a significant intercept, $F(1,32)=14.48, p=.001, \eta_{\mathrm{p}}{ }^{2}=.311$, indicating overall a significant compatibility effect with faster responses in compatible than incompatible trials; the horizontal as well as the vertical compatibility effect were equally pronounced and both significant, $t(33)=3.00, p=.005$, and $t(33)=3.72, p<.001$, respectively.

\section{Discussion}

In Experiment 4, we compared Japanese and German subjects in two SOA conditions with horizontal as well as vertical motion primes in a response priming experiment. In the short SOA condition, we found larger horizontal than vertical PCEs in both samples. In the longer SOA condition, we found reduced, but nevertheless positive compatibility effects-most pronounced with vertical materials in the Japanese sample (but not significantly differing from the German sample and not differing from the horizontal orientation). The reduced compatibility effects (driven by the German sample) in the longer SOA matched our expectations, based on previous studies (see above). Before interpreting our results, especially in terms of reading/writing experience, we corroborate our results by presenting a combined analysis of Experiments 2 to 4 .

\section{COMBINED ANALYSES}

Given the similarities across Experiments 2, 3, and 4, we decided to combine the data to allow for a more comprehensive analysis. To combine the data, we collapsed three SOA levels $(350 \mathrm{~ms}, 550 \mathrm{~ms}$, and $750 \mathrm{~ms}$ ) to one SOA level (i.e., longer SOAs). Then, we performed a repeated-measures ANOVA for compatibility effects with country (Germany, Malaysia, Japan) and SOA (short SOA, longer SOAs) as 
between-subjects variables and orientation (horizontal, vertical) as within-subjects variable.

This ANOVA revealed a significant intercept, $F(1,296)=181.85$, $p<.001, \eta_{\mathrm{p}}{ }^{2}=.381$, indicating faster responses to compatible than incompatible trials. The main effect of SOA was significant as well, $F(1$, 296) $=23.25, p<.001, \eta_{p}{ }^{2}=.073$ : there were larger compatibility effects in the short compared to the longer SOA conditions. This main effect was qualified by significant interactions of orientation and SOA, $F(1$, 296) $=11.13, p=.001, \eta_{\mathrm{p}}{ }^{2}=.036$, as well as country and SOA, $F(2$, 296) $=4.14, p=.017, \eta_{\mathrm{p}}{ }^{2}=.027$. All other effects were not significant, ps $>.13$.

To clarify these interactions, we first tested the compatibility effects for the horizontal versus vertical orientation against each other, separately for the SOA levels. There were larger horizontal $(M=21 \mathrm{~ms}, S E$ $=1.69, t[102]=12.49, p<.001)$ than vertical $(M=16 \mathrm{~ms}, S E=1.59$, $t[102]=9.88, p<.001)$ compatibility effects in the short SOA condition, $t(102)=2.65, p=.009$, and larger vertical $(M=7 \mathrm{~ms}, S E=1.21$, $t[198]=5.75, p<.001)$ than horizontal $(M=4 \mathrm{~ms}, S E=1.15, t[198]$ $=3.82, p<.001)$ compatibility effects in the longer SOA conditions, $t(198)=2.05, p=.042$.

Second, we tested the compatibility effects from the subjects of the three countries against each other, separately for each SOA. The compatibility effects of the German and Malaysian sample did not differ significantly, neither in the short nor in the longer SOAs, $p s>$ .38. Furthermore, there were no differences in the short SOA condition between the German and the Japanese samples as well as between the Malaysian and Japanese samples, $p s>.51$. In the longer SOA condition, however, there were significantly larger compatibility effects in the Japanese sample compared to the German, $t(130)=3.03, p=.003$, as well as to the Malaysian sample, $t(83)=3.14, p=.002$.

\section{GENERAL DISCUSSION}

In the present study, we tested subjects from three different countries (Experiments 1 to 4: Germany, Experiment 3: Malaysia, Experiment 4: Japan) in response priming experiments using vertically and/or horizontally moving primes and static arrow targets. We used four different SOAs between prime and target: 150/160 ms (Experiments 1 to 4 ), 350/360 ms (Experiments 1 to 4), $550 \mathrm{~ms}$ (Experiments 2 and 3), and $750 \mathrm{~ms}$ (Experiment 3). Overall, we could replicate the general pattern of results observed in previous research with motion primes in response priming (e.g., Bermeitinger, 2013)—we found pronounced PCEs with short SOAs and reduced or no compatibility effects with longer SOAs. In the present study, however, we found no evidence for NCEs, not even with horizontally moving primes and long SOAs of 550 or $750 \mathrm{~ms}$. The lack of NCEs might be explained by the use of different equipment-especially compared to our previous experiments-and motion times (e.g., other refresh rates resulting in longer presentation times of each single slide). Positive compatibility effects are generally much more stable and they can be expected irrespective of mechanisms possibly influenced by differences in the presentation parameters of the screens. Therefore, it seems not unusual that we found the typical PCEs in short SOAs.

The present study had three aims. The first aim was to examine whether response priming, previously observed with horizontal movements (e.g., Bermeitinger, 2013), could also be observed with vertical movements. Across all four experiments, we found compatibility effects in vertically oriented materials where subjects responded faster to targets if they were primed in the same direction.

The second aim of the present study was to examine whether response priming with vertical materials showed the same time course as response priming with horizontal materials. In general, it seems that the compatibility effect was larger for horizontally oriented materials at short SOAs and larger for vertically oriented materials at longer SOAs. Although we observed a similar pattern with larger PCEs at short SOAs and smaller or no PCEs at longer SOAs, there were some differences with the results of previous studies.

Especially with vertical motions, but even with horizontal motions (e.g., the Malaysian sample in Experiment 3), there seemed to be a rebound effect-after PCEs with short SOAs, compatibility effects were reduced to zero in medium-sized SOAs, and with long SOAs (especially $750 \mathrm{~ms}$, see Experiment 3), there were again PCEs. This finding is in contrast to previous studies with horizontal motions which (most often) found NCEs with longer SOAs (e.g., Bermeitinger, 2013; Bermeitinger \& Wentura, 2016; but see e.g., Bermeitinger \& Hackländer, 2018). In the current study, the PCEs in short SOA conditions seem to reflect automatic pre-activations, whereas the PCEs with the longest SOAs could be explained by expectancy-based theories (e.g., Becker, 1980, on semantic priming). These accounts assume that subjects use the prime to generate a set of potential targets related to the prime. Responses that are included within this expectancy set are faster recognised than responses that are not included. This process is most often assumed as being relatively slow acting (compared to fast acting motor pre-activations), under strategic control, and requiring the subject's awareness and/or intention.

The third aim of the present study was to examine the influence of experience, training, and/or use of different orientations in daily life on the pre-activations for vertical/horizontal materials. More specifically, we tested whether the compatibility effect for vertically oriented materials would be larger for subjects who would be more accustomed to read and/or write vertically (i.e., Chinese Malaysian and Japanese students). We could confirm that there were differences in reading/writing experience between the German sample and both other samples (especially the frequency of reading vertically and the time reading/ writing vertically differed as expected, see Table 4). However, we found no overall differences in compatibility effects between the German and Malaysian subjects. In contrast, there were larger PCEs in the Japanese subjects (compared to German and Malaysian subjects) in the longer SOA condition (overall for vertical as well as horizontal stimuli) but not in the short SOA condition. There were no other substantial differences between the subjects from the three countries. This finding seems to reflect a generally higher pre-activation by motion or prime 
stimuli in the Japanese sample, but it cannot properly be interpreted in terms of facilitation due to differences in reading/writing experience.

In general, we should not over-interpret this finding due to several reasons. First, the Japanese sample was tested in only two SOA conditions (150 and $350 \mathrm{~ms}$ ). Perhaps, more pronounced differences may appear at longer SOAs. Second, it also must be noted that the subjects in Experiments 2 to 4 received verbal instructions recorded in English (rather than in German, Chinese, or Japanese). Perhaps differences may emerge when (verbal) instructions are presented in the subjects' native language and/or in another manner that reduces (left/right or up/down) biases due to the instruction language.

Although we see our results not as strong evidence for cultural influence on the processing of motions or on the pre-activation for verti$\mathrm{cal} /$ horizontal material, it might be fruitful to integrate them with the findings regarding cultural or linguistic influences on visual attention. For example, there is evidence that people from East Asian cultures attend more and earlier to the context and to the relationship between several stimuli compared to people from Western cultures. Further, they have more problems ignoring irrelevant context information. Overall, this leads to a holistic perception (for a review see Nisbett \& Miyamoto, 2005). This might also explain the overall larger compatibility effects in our Japanese sample compared to our German sample: the Japanese subjects especially might attend to the context (i.e., the prime) more than the German subjects, and they might integrate the primes more to the whole scene including the response-relevant object (i.e., the target) compared to the German subjects.

\section{Theoretical Implications}

Our overall result of larger horizontal than vertical compatibility effects fits well with findings from other experiments using static stimuli and/or other paradigms showing the so-called left/right prevalence (e.g., Klauer \& Dittrich, 2010; Nicoletti \& Umiltà, 1984, 1985; Nicoletti et al., 1988; Rubichi et al., 2005; Rubichi et al., 2006; Vallesi et al., 2005; Wiegand \& Wascher, 2005). This difference was, however, only obvious in the short SOA condition. In the longer SOA conditions, the compatibility effects with vertical materials were equally pronounced or even larger than the compatibility effects with horizontal materials, independent of country/sample. These findings seem to suggest that fast (and possibly automatic) activation processes are still faster with horizontal than vertical materials, but when time-consuming processes come into play, responses to vertical materials are more strongly influenced.

As there were no large differences between the samples, the results cannot be explained by the role of training of the left-right versus updown orientation (Rubichi et al., 2005; Taguchi, 2010). There are some other explanations that can explain differences between horizontal and vertical spatial compatibility effects, for example different neural mechanisms (e.g., Vallesi et al., 2005; Wiegand \& Wascher, 2005) or differences in spatial coding (e.g., Rubichi et al., 2005; Rubichi et al., 2006). However, as our results cannot contribute to decide between those explanations, we refrain from discussing them further.
Furthermore, experiments with horizontal versus vertical materials often include a difference in the necessity of switching between planes. Most often (also in our study), the response has to be given in the axial plane whereas stimuli are presented in the frontal plane. With horizontal materials, no switch is needed between the perceptual and motor plane. In contrast, with vertical materials, one has to mentally rotate the plane before responding. Possibly, this incongruence or increased effort might explain the generally reduced compatibility effects with vertical stimuli in the short SOA in our experiments (see also Klauer \& Dittrich, 2010, using static materials and left or right responses to up or down targets). Future studies using motion primes could orthogonally manipulate whether subjects have to switch the planes or not and the orientation of the materials to investigate the impact of the necessity to switch between planes.

The observed PCEs can be explained by common theories on compatibility effects, such as the action-trigger theory (e.g., Kiesel et al., 2007; Kunde et al., 2003); (motor) pre-activations caused by the prime lead to response advantages when a compatible target has to be classified, and there are motor conflicts generated by motor activations from the prime as well as the target, resulting in slower responses in case of incompatible targets. As we did not find any NCEs, we will not discuss our results against the background of theories on NCEs. Instead, in the following section, we discuss our results with respect to attentional mechanisms.

Largest PCEs observed at the shortest SOA (i.e., 150/160 ms) are also in agreement with the pattern of results typically observed in the Posner cueing paradigm. At CTOAs shorter than $200 \mathrm{~ms}$, faster behavioural responses to previously attended locations have been found regardless of response modality, that is, manual or saccadic response to the target (Briand et al., 2000; Klein, 2000). Our results showed similar behavioural facilitation effects (i.e., PCEs) at short SOAs. Although the time course of the PCEs observed across our experiments is not identical to that of cueing and IOR, the decline of early PCEs as SOA increases can also be seen in the behavioural cueing studies (e.g., Klein, 2000).

The typical pattern of positive or facilitatory cueing effects with CTOAs shorter than $200 \mathrm{~ms}$ and inhibitory or negative cueing effects (i.e., IOR) with CTOAs above $200 \mathrm{~ms}$ is usually found with cues presented at one of the target locations (e.g., left or right from the central fixation). The finding of positive cueing effects with short CTOAs has been interpreted as evidence for reflexive and automatic attentional shifts. Despite the fact that centrally presented arrow cues in the Posner cueing paradigm have been found to direct attention involuntarily (Hommel et al., 2001; Pratt \& Hommel, 2003), no study has demonstrated a similar cueing effect at CTOAs shorter than about $200 \mathrm{~ms}$. On the other hand, Friesen and Kingstone (1998) found positive cueing effects with CTOAs as early as $105 \mathrm{~ms}$ following the onset of an eye gaze cue (i.e., a schematic line drawing of a face with pupils looking leftwards or rightwards).

Although the findings from Friesen and Kingstone (1998) seem to suggest that such eye gaze cues could produce reflexive shifts of attention even if arrow cues do not, later studies have found that the 
early positive cueing effects were only observable when the cue and target stimuli remained on the screen together until the behavioural response has been made (e.g., Green et al., 2013; Green \& Woldorff, 2012). In the study by Green et al. (2013), early positive cueing effects were found at short CTOAs of $0 \mathrm{~ms}$ and $100 \mathrm{~ms}$ regardless of cue type (i.e., eye gaze and arrow cues) when the cue was presented together with the target until a response was given. However, when the cue duration was only $50 \mathrm{~ms}$, no significant cueing effect was found across all SOAs of $0 \mathrm{~ms}, 100 \mathrm{~ms}, 300 \mathrm{~ms}$, and $500 \mathrm{~ms}$. These findings suggest that the early cueing effects were not caused by rapid reflexive shifts of attention to primed locations but by slower processes, probably causing slowed responses to uncued targets in the case of incongruent spatial information.

In the present study, we found PCEs at SOA as short as $150 \mathrm{~ms}$ across all samples, even when the duration of motion primes was only 133.33 ms. The spatial-conflict account (e.g., Green et al., 2013; Green \& Woldorff, 2012), therefore, cannot be used to explain our findings as there was no temporal overlap between the cue and target stimuli, suggesting either that motion primes can trigger reflexive shifts of spatial attention better than eye gaze and arrow cues or that the compatibility effects from response priming (even with motion primes) are independent of attentional shifts (see also Bermeitinger et al., 2019).

\section{Conclusions}

Taken together, the present findings from response priming experiments using horizontally versus vertically oriented materials and motion primes in samples from three different countries with more or less experience with the vertical direction in daily life suggest that the horizontal direction is more pronounced in early processing, and the vertical direction has more impact with increasing processing time, irrespective of experience and daily training with the vertical direction. This finding seems independent of reflexive attentional shifts towards spatial locations. In contrast, motor pre-activations-that are initialized faster or slower by horizontal versus vertical motions, respectively-are plausible candidates for the pattern we found. With longer SOAs, either a counter-regulation or a simple decay of those pre-activations (Bermeitinger \& Kappes, 2018) could explain the reduced compatibility effects. The rebound with awakened PCEs at longest SOAs might be due to strategical and voluntary processes by the subjects. However, the interplay of attentional mechanisms, response-based processes, as well as voluntary strategies with horizontal versus vertical motions should be investigated further in future studies.

\section{ETHICAL APPROVAL}

All procedures performed in our experiments involving human subjects were in accordance with the ethical standards of the institutional and/or national research committees and with the 1964 Declaration of Helsinki and its later amendments or comparable ethical standards. Our subjects were verbally informed about the experiment and their rights as a research participant. All subjects gave written informed consent. The experiments reported here were approved by the Local Ethical
Committee of the Faculty 1 at the University of Hildesheim (all experiments) as well as the Science and Engineering Research Ethics Committee of the University of Nottingham Malaysia (Experiment 3). Experiment 4 was conducted in agreement and in coordination with our contact person at the Dokkyo University, Tokio (Japan).

\section{ACKNOWLEDGEMENTS}

Hannah Goymann, Laura Kalbfleisch, Lea Reuter, Katharina Schäfer, and Anna Schliephake conducted Experiment 1 during the course "Wissenschaftliche Praxis" that is part of the Bachelor of Psychology programme at the University of Hildesheim. We are grateful to them for preparing the experiments and collecting the data. The research was funded by a grant from the Deutsche Forschungsgemeinschaft (DFG; German Research Foundation) to Christina Bermeitinger (BE 4851/3-1), and by travelling grants from the International Office of the University of Hildesheim to Laura Kalbfleisch and Katharina Schäfer. The data are available here: Bermeitinger, C., Goymann, H., Lim, A., Schäfer, K., Janssen, S., Reuter, L., Kalbfleisch, L. (2020). Data for: Response priming with horizontally and vertically moving primes: A comparison of German, Malaysian, and Japanese subjects. Mendeley Data, V1, doi: 10.17632/m6pgkwy7rs.1.

\section{REFERENCES}

Abed, F. (1991). Cultural influences on visual scanning patterns. Journal of Cross-Cultural Psychology, 22, 525-534. doi:

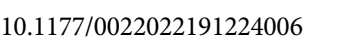

Becker, C. A. (1980). Semantic context effects in visual word recognition: An analysis of semantic strategies. Memory \& Cognition, 8, 493-512. doi: 10.3758/BF03213769 السلسلس

Bermeitinger, C. (2013). Response priming with apparent motion primes. Psychological Research, 77, 371-387. doi: 10.1007/s00426012-0436-x - ل1

Bermeitinger, C., Baess, P., Eckert, D., \& Rey-Mermet, A. (2019). Response priming with motion primes containing two spatialdirectional dimensions. Manuscript in preparation.

Bermeitinger, C., \& Hackländer, R. P. (2018). Response priming with motion primes: Negative compatibility or congruency effects, even in free-choice trials. Cognitive Processing, 19, 351-361. doi: 10.1007/ s10339-018-0858-5 سلس

Bermeitinger, C., \& Kappes, C. (2018). Activation, inhibition, or something else: An exploratory study on response priming using moving dots as primes in middle-age and old adults. Journal of Aging Research, 7432602. doi: 10.1155/2018/7432602 سلس

Bermeitinger, C., \& Wentura, D. (2016). Moving single dots as primes for static arrow targets: Negative compatibility effects at very long SOAs. Experimental Psychology, 63, 127-139. doi: 10.1027/16183169/a000321 سلسلسلس

Berthoz, A., \& Viaud-Delmon, I. (1999). Multisensory integration in spatial orientation. Current Opinion in Neurobiology, 9, 708-712. doi:

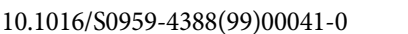


Briand, K. A., Larrison, A. L., \& Sereno, A. B. (2000). Inhibition of return in manual and saccadic response systems. Perception \& Psychophysics, 62, 1512-1524. doi: 10.3758/BF03212152 الم

Chan, T., \& Bergen, B. (2005). Writing direction influences spatial cognition. In B. G. Bara, L. Barsalou, \& M. Buchiarelli (Eds.), Proceedings of the Twenty-Seventh Annual Meeting of the Cognitive Science Society (pp. 412-417). Lawrence Erlbaum Associates.

Chokron, S., \& De Agostini, M. (2000). Reading habits influence aesthetic preference. Cognitive Brain Research, 10(1-2), 45-49. doi:

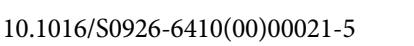

Eimer, M., \& Schlaghecken, F. (2002). Links between conscious awareness and response inhibition: Evidence from masked priming. Psychonomic Bulletin \& Review, 9, 514-520. doi: 10.3758/

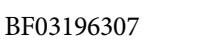

Fagard, J., \& Dahmen, R. (2003). The effects of reading-writing direction on the asymmetry of space perception and directional tendencies: A comparison between French and Tunisian children. Laterality, 8, 39-52. doi: 10.1080/713754473 المالسلسلا

Faul, F., Erdfelder, E., Lang, A. G., \& Buchner, A. (2007). G*Power 3: A flexible statistical power analysis program for the social, behavioral, and biomedical sciences. Behavior Research Methods, 39, 175-191. doi: 10.3758/BF03193146 المسلسلس

Friesen, C. K., \& Kingstone, A. (1998). The eyes have it! Reflexive orienting is triggered by nonpredictive gaze. Psychonomic Bulletin \& Review, 5, 490-495. doi: 10.3758/BF03208827 |لاسلس

Green, J. J., Gamble, M. L., \& Woldorff, M. G. (2013). Resolving conflicting views: Gaze and arrow cues do not trigger rapid reflexive shifts of attention. Visual Cognition, 21, 61-71. doi: 10.1080/13506285.2013.775209 الميلس

Green, J. J., \& Woldorff, M. G. (2012). Arrow-elicited cueing effects at short intervals: Rapid attentional orienting or cue-target stimulus conflict? Cognition, 122, 96-101. doi: 10.1016/j.cogni-

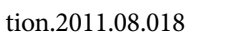

Hackländer, R., Eckert, D., \& Bermeitinger, C. (2015). Visual processing: The role of importance. In T. Heinen (Ed.), Advances in visual perception research (pp. 1-28). Nova Publishing.

Hilchey, M. D., Klein, R. M., \& Satel, J. (2014). Returning to 'inhibition of return' by dissociating long-term oculomotor IOR from shortterm sensory adaptation and other nonoculomotor 'inhibitory' cueing effects. Journal of Experimental Psychology: Human Perception and Performance, 40, 1603-1616. doi: 10.1037/a0036859 السلس

Hommel, B., Pratt, J., Colzato, L., \& Godijn, R. (2001). Symbolic control of visual attention. Psychological Science, 12, 360-365. doi: 10.1111/1467-9280.00367 سلس

IBM Corp. (Released 2018). IBM SPSS Statistics for Windows, Version 26.0. IBM Corp.

Ishii, Y., Okubo, M., Nicholls, M. E., \& Imai, H. (2011). Lateral biases and reading direction: A dissociation between aesthetic preference and line bisection. Brain and Cognition, 75, 242-247. doi: 10.1016/j. bandc.2010.12.005 سلس

Jaśkowski, P., Białuńska, A., Tomanek, M., \& Verleger, R. (2008). Mask- and distractor-triggered inhibitory processes in the priming of motor response: An EEG study. Psychophysiology, 45, 70-85. doi: 10.1111/j.1469-8986.2007.00595.x المبلسلس

Kiesel, A., Kunde, W., \& Hoffmann, J. (2007). Mechanisms of subliminal response priming. Advances in Cognitive Psychology, 3(1-2), 307-315. doi: 10.2478/v10053-008-0032-1 السلس

Klapp, S. T. (2005). Two versions of the negative compatibility effect: Comment on Lleras and Enns (2004). Journal of Experimental Psychology: General, 134, 431-440. doi: 10.1037/00963445.134.3.431 (لسلسل

Klauer, K. C., \& Dittrich, K. (2010). From sunshine to double arrows: An evaluation window account of negative compatibility effects. Journal of Experimental Psychology: General, 139, 490-519. doi: 10.1037/a0019746 المالسلس الم

Klein, R. M. (2000). Inhibition of return. Trends in Cognitive Sciences, 4, 138-147. doi: 10.1016/S1364-6613(00)01452-2 اله السلس

Kunde, W., Kiesel, A., \& Hoffmann, J. (2003). Conscious control over the content of unconscious cognition. Cognition, 88, 223-242. doi: 10.1016/S0010-0277(03)00023-4 الس السلاسل

Lim, A., Eng, V., Janssen, S. M. J., \& Satel, J. (2018). Sensory adaptation and inhibition of return: Dissociating multiple inhibitory cueing effects. Experimental Brain Research, 236, 1369-1382. doi: 10.1007/

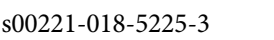

Lingnau, A., \& Vorberg, D. (2005). The time course of response inhibition in masked priming. Perception \& Psychophysics, 67, 545-557. doi:

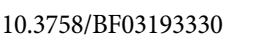

Liu, C.-H., Lee, C.-F., \& Lee, H.-L. (2013). Exploring the relationship between reading habits and aesthetic preferences in different cultural contexts and design practices. Actas 5th IASDR, 2013 Tokyo, 5019-5026. الم

Lleras, A., \& Enns, J. T. (2004). Negative compatibility or object updating? A cautionary tale of mask-dependent priming. Journal of Experimental Psychology: General, 133, 475-493. doi: 10.1037/00963445.133.4.475 المسلس

Maass, A., \& Russo, A. (2003). Directional bias in the mental representation of spatial events: Nature or culture? Psychological Science, 14, 296-301. doi: 10.1111/1467-9280.14421 الس

Machado, L., Wyatt, N., Devine, A., \& Knight, B. (2007). Action planning in the presence of distracting stimuli: An investigation into the time course of distractor effects. Journal of Experimental Psychology: Human Perception and Performance, 33, 1045-1061. doi: 10.1037/0096-1523.33.5.1045 الس السلس

Mattler, U., \& Fendrich, R. (2007). Priming by motion too rapid to be consciously seen. Perception \& Psychophysics, 69, 1389-1396. doi: 10.3758/BF03192954 سلس

Neumann, O. (1990). Direct parameter specification and the concept of perception. Psychological Research, 52, 207-215. doi: 10.1007/ BF00877529 سلس الم

Nicoletti, R., \& Umiltà, C. (1984). Right-left prevalence in spatial compatibility. Perception \& Psychophysics, 35, 333-343. doi: 10.3758/ BF03206337 每

Nicoletti, R., \& Umiltà, C. (1985). Responding with hand and foot: The right/left prevalence in spatial compatibility is still present. Perception, 
\& Psychophysics, 38, 211-216. doi: 10.3758/BF03207147 |سلس

Nicoletti, R., Umiltà, C., Tressoldi, E. P., \& Marzi, C. A. (1988). Why are left-right spatial codes easier to form than above-below ones? Perception \& Psychophysics, 43, 287-292. doi: 10.3758/BF03207872 السلسلس

Nisbett, R. E., \& Miyamoto, Y. (2005). The influence of culture: Holistic versus analytic perception. Trends in Cognitive Sciences, 9, 467-473. doi: 10.1016/j.tics.2005.08.004 الم

Posner, M. I. (1980). Orienting of attention. Quarterly Journal of Experimental Psychology, 32, 3-25. doi: 10.1080/00335558008248231 المسلسلس

Posner, M. I., Rafal, R. D., Choate, L. S., \& Vaughan, J. (1985). Inhibition of return: Neural basis and function. Cognitive Neuropsychology, 2, 211-228. doi: 10.1080/02643298508252866 إلس الس

Pratt, J., \& Hommel, B. (2003). Symbolic control of visual attention: The role of working memory and attentional control settings. Journal of Experimental Psychology: Human Perception and Performance, 29, 835-845. doi: 10.1037/0096-1523.29.5.835 سلس

Rubichi, S., Nicoletti, R., \& Umiltà, C. (2005). Right-left prevalence with task-irrelevant spatial codes. Psychological Research, 69, 167178. doi: 10.1007/s00426-003-0168-z الس السلسل

Rubichi, S., Vu, K.-P. L., Nicoletti, R., \& Proctor, R. W. (2006). Spatial coding in two dimensions. Psychonomic Bulletin \& Review, 13, 201-216. doi: 10.3758/BF03193832 سلس

Sarkheil, P., Vuong, Q. C., Bülthoff, H. H., \& Noppeney, U. (2008). The integration of higher order form and motion by the human brain.

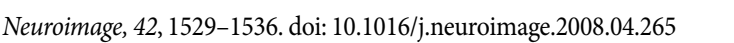
Schlaghecken, F., \& Eimer, M. (2002). Motor activation with and without inhibition: Evidence for a threshold mechanism in motor control. Perception \& Psychophysics, 64, 148-162. doi: 10.3758/ BF03194564 سلس

Schlaghecken, F., \& Eimer, M. (2006). Active masks and active inhibition: A comment on Lleras and Enns (2004) and on Verleger, Jaśkowski, Aydemir, van der Lubbe, and Groen (2004). Journal of Experimental Psychology: General, 135, 484-494. doi: 10.1037/00963445.135.3.484 |سلس
Schlaghecken, F., Klapp, S. T., \& Maylor, E. A. (2009). Either or neither, but not both: Locating the effect of masked priming. Proceedings of

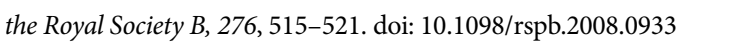
Schmidt, F., Haberkamp, A., \& Schmidt, T. (2011). Dos and don'ts in response priming research. Advances in Cognitive Psychology, 7, 120-131. doi: 10.2478/v10053-008-0092-2 25ل

Schmidt, T., Niehaus, S., \& Nagel, A. (2006). Primes and target in rapid chases: Tracing sequential waves of motor activation. Behavioral Neuroscience, 120, 1005-1016. doi: 10.1037/0735-7044.120.5.1005 البلسلسلس Spalek, T. M., \& Hammad, S. (2005). The left-to-right bias in inhibition of return is due to the direction of reading. Psychological Science, 16, 15-18. doi: 10.1111/j.0956-7976.2005.00774.x السلسلس الس الس

Taguchi, M. (2010). Cultural differences in drawing movements between right-handed Japanese and German participants. Psychological Reports, 107, 329-335. doi: 10.2466/10.23.25. PR0.107.4.329-335 سلس

Treiman, R., \& Allaith, Z. (2013). Do reading habits influence aesthetic preferences? Reading and Writing, 26, 1381-1386. doi: 10.1007/ s11145-012-9424-1 المالسل

Tukey, J. W. (1977). Exploratory data analysis. Addison-Wesley.

Vallesi, A., Mapelli, D., Schiff, S., Amodio, P., \& Umiltà, C. (2005). Horizontal and vertical Simon effect: Different underlying mechanisms? Cognition, 96, B33-B43. doi: 10.1016/j.cognition.2004.11.009 الم

Wiegand, K., \& Wascher, E. (2005). Dynamic aspects of stimulusresponse correspondence: Evidence for two mechanisms involved in the Simon effect. Journal of Experimental Psychology: Human Perception and Performance, 31, 453-464. doi: 10.1037/00961523.31.3.453

RECEIVED 24.09.2019 | ACCEPTED 18.03.2020 